\title{
Corrosion/Electrochemistry of Monocrystalline and Polycrystalline Beryllium in Aqueous Chloride Environment
}

Jeffrey R. Friedman

James E. Hanafee

Chemistry and Material Science Directorate Materials Science and Technology Division

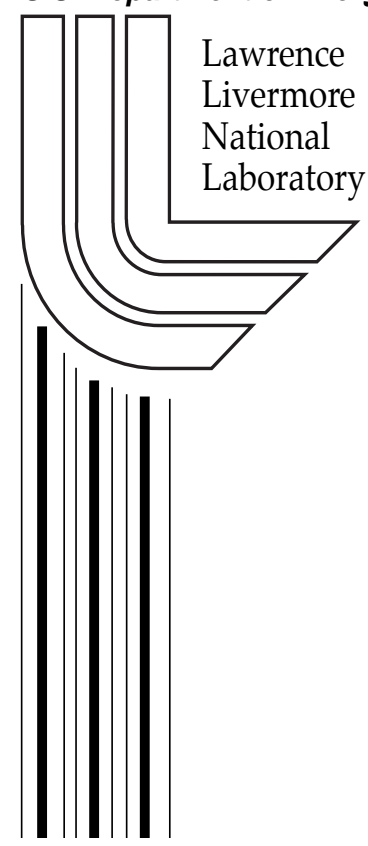

January 2000 


\section{DISCLAIMER}

This document was prepared as an account of work sponsored by an agency of the United States Government. Neither the United States Government nor the University of California nor any of their employees, makes any warranty, express or implied, or assumes any legal liability or responsibility for the accuracy, completeness, or usefulness of any information, apparatus, product, or process disclosed, or represents that its use would not infringe privately owned rights. Reference herein to any specific commercial product, process, or service by trade name, trademark, manufacturer, or otherwise, does not necessarily constitute or imply its endorsement, recommendation, or favoring by the United States Government or the University of California. The views and opinions of authors expressed herein do not necessarily state or reflect those of the United States Government or the University of California, and shall not be used for advertising or product endorsement purposes.

Work performed under the auspices of the U. S. Department of Energy by the University of California Lawrence Livermore National Laboratory under Contract W-7405-Eng-48.

This report has been reproduced

directly from the best available copy.

Available to DOE and DOE contractors from the

Office of Scientific and Technical Information

P.O. Box 62, Oak Ridge, TN 37831

Prices available from (423) 576-8401

http: / / apollo.osti.gov/bridge /

Available to the public from the National Technical Information Service

U.S. Department of Commerce 5285 Port Royal Rd., Springfield, VA 22161

http://www.ntis.gov/

OR

Lawrence Livermore National Laboratory

Technical Information Department's Digital Library

http:/ / www.llnl.gov/tid/Library.html 


\title{
CORROSION/ELECTROCHEMISTRY OF MONOCRYSTALLINE AND POLYCRYSTALLINE BERYLLIUM IN AQUEOUS CHLORIDE ENVIRONMENT
}

\begin{abstract}
$\underline{\text { Abstract }}$
Corrosion characteristics of high-purity polycrystalline beryllium as a function of $\mathrm{pH}$ and $\mathrm{NaCl}$ concentration were studied at $25^{\circ} \mathrm{C}$, using cyclic polarization tests. Single crystal beryllium specimens oriented close to the (0001), (1010), and (1120) planes using Laue back reflection techniques were studied using cyclic polarization tests in $0.01 \mathrm{M} \mathrm{NaCl}$ with a nominal $\mathrm{pH}$ of 7 . Pit morphology of the polycrystalline and single crystals was studied using conventional scanning electron microscopy. On the polycrystalline specimens, passivity appears to be more a function of solution $\mathrm{pH}$ than of chloride concentration. Single crystal studies show dramatic differences in cyclic polarization plots and SEM micrographs. The two prism planes (1010) and (1120) behave similarly while the basal plane (0001) behaved in a substantially different manner.
\end{abstract}

\section{Introduction}

Unalloyed beryllium metal components are ordinarily of high value, and they are used in unique applications. Usually, the applications are such that the beryllium components are protected from adverse corrosive environments and, if this is not possible, coatings are applied to improve the corrosion resistance. In addition, the inherent corrosion resistance of beryllium is excellent. The thin oxide film on beryllium is strong, thin, and adherent; it provides good protection for the underlying metal. Unalloyed beryllium is not a commonly used metal, such as steel or perhaps aluminum, copper, or nickel based alloys. The net result of all these factors is that there is not a broad base knowledge of the corrosion behavior of beryllium. It is known that beryllium is sensitive to pitting corrosion in some moist environments. The pitting may be stimulated by the presence of other elements such as chloride ions. This is common for many metals. Also, it is well known that beryllium carbides, a common inclusion in some grades of beryllium, react with moisture in the air to form beryllium oxide and methane.

Beryllium is highly anisotropic. The basic cause is the electronic structure, and the anisotropy is reflected in both mechanical and physical properties. It is reasonable to hypothesize that the corrosion properties would also be anisotropic.

To partially circumvent the anisotropy, most structural grades of beryllium are made by powder metallurgy. The basic processing is conventional. The beryllium is made into a powder and then consolidated by vacuum hot pressing, cold isostatic pressing, hot isostatic pressing, or some combination of these consolidation processes. The beryllium component is subsequently machined from the pressed block. Due to the shape of the powder particles and (to a lesser extent) the mechanical properties, there is still a tendency for some anisotropy in the pressed block, with the basal planes tending to be perpendicular to the axis of the die, or (for the isostatic pressing) the axis of the container. This occurs mainly in the powder-loading step, and it can be aggravated in the vacuum hot pressing operation. Improvements in the processing have minimized the anisotropy of pressed blocks; however, there is still some anisotropy in most beryllium pressed blocks. There is also the issue of older beryllium components with a stronger crystallographic texture still in service, or in storage under less than desirable environments.

Another common form of beryllium is sheet and foil. In the fabrication process, a strong basal texture forms, with the basal planes tending to lie parallel in the plane of the sheet. Similarly, recent new applications of beryllium involve beryllium-aluminum alloys with 55\% to $65 \%$ 
beryllium. The fabrication methods are rolling or extrusion. In both cases, the beryllium phase will tend to have a basal texture in the plane of the sheet or plate. As for the pressed block, if corrosion is different for different crystallographic planes, then the corrosion of these products may differ substantially from the plane of the sheet (or plate) to the edge of the sheet (or plate). Preliminary corrosion work at LANL with polycrystalline beryllium samples suggests preferential corrosion on certain crystal orientations. Varying corrosion rates on the different crystallographic orientation might be explained due to the planer density of the atoms in the lattice. If this was the case, one would expect that the (0001) basal plane has the most resistance to corrosion, while the two prismatic planes will have the least resistance to corrosion.

If corrosion of beryllium pressed block, sheet or plate, or the beryllium-aluminum alloys is anisotropic, then it would be expected that corrosion of a beryllium or beryllium alloy component may differ from one orientation to another. In practical situations, there are many variables, and if corrosion occurs, it would be useful to know if one variable is the crystallographic texture. This would permit concentration on the cause of the corrosion and, perhaps, suggest modifications to prevent additional corrosion.

There are conventional corrosion tests that could be applied to polycrystalline beryllium shapes and components. Eventually, this empirical approach would yield positive results. A simpler set of experiments may provide a more definitive answer. Specifically, we have used high-purity, single crystals oriented with surfaces oriented parallel to the three principal crystallographic planes; viz., the basal plane (0001) and the two prismatic planes (1120) and (1010), shown in Figure 1. Use of this type of specimen will clearly differentiate between different crystallographic planes, and it will eliminate possible corrosion at localized sites, such as grain boundaries and inclusions. The corrosion behavior was determined in an aqueous solution in a potentiostat. The surfaces of the single crystals were characterized using optical microscopy and scanning electron microscopy before and after exposure to the corrosive media.

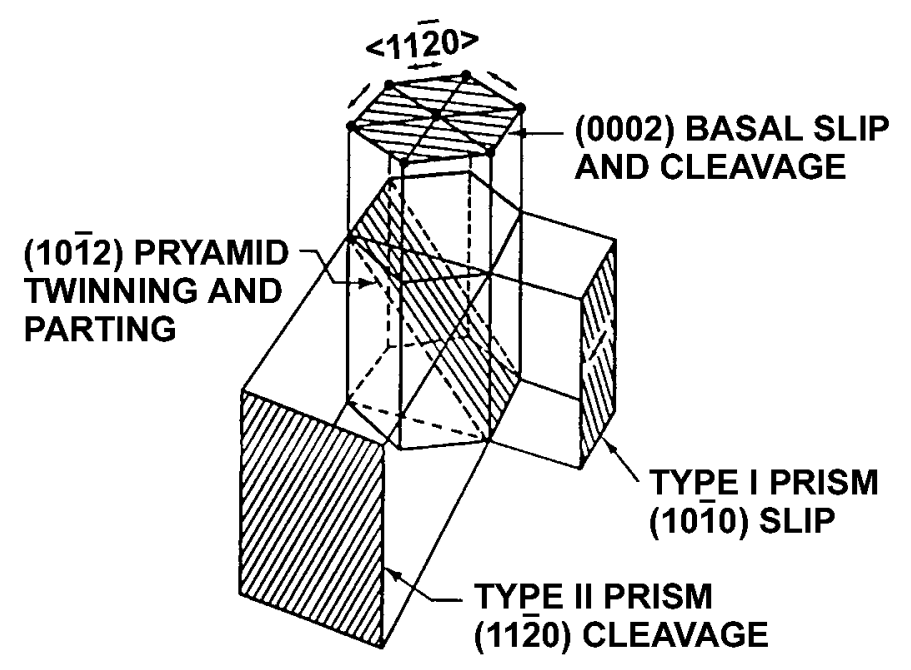

Figure 1. Diagram of Beryllium Unit Cell 


\section{Apparatus and Reagents}

The apparatus used in our beryllium experiments is similar to that used in ASTM G-5 and ASTM G-61 corrosion tests. The polarization cell has a capacity of one liter and has appropriate openings for Lugen Probe, counter electrodes, electrode, and gas inlet/outlet tubes. Polycrystalline samples required a standard Teflon electrode holder that exposed only the polished surface. Single crystal experiments required a custom-made electrode holder due to the irregular shape of specimens, as shown in Figure 2. The single crystals were mounted in cold curing epoxy, leaving only the surface of the crystals exposed. Before being mounted in the epoxy, the single crystals were glued to Teflon ${ }^{\circledR}$ coated stainless steel rods using conductive epoxy. The outer perimeter of the beryllium single crystals were painted with a cellulose acetate resin to eliminate any crevice corrosion which could have occurred at the interface between the cold curing epoxy and the beryllium metal.

The polarization cell was immersed to within $1 \mathrm{~cm}$ of solution/electrolyte level in a waterbath kept at $\pm 1{ }^{\circ} \mathrm{C}$ of desired temperature. An EG\&G Princeton Applied Research Model 273 potentiostat was used to control the electrode potential to within $1 \mathrm{mV}$ of programmed values. Potential and current data were sent to a Gateway2000 P5-90 and recorded for graphical analysis using 352 SoftcorrIII software.

Reagent grade $\mathrm{NaCl}$ was used in solutions of varying concentration according to experimental procedure. Deionized water was used to prepare solutions.

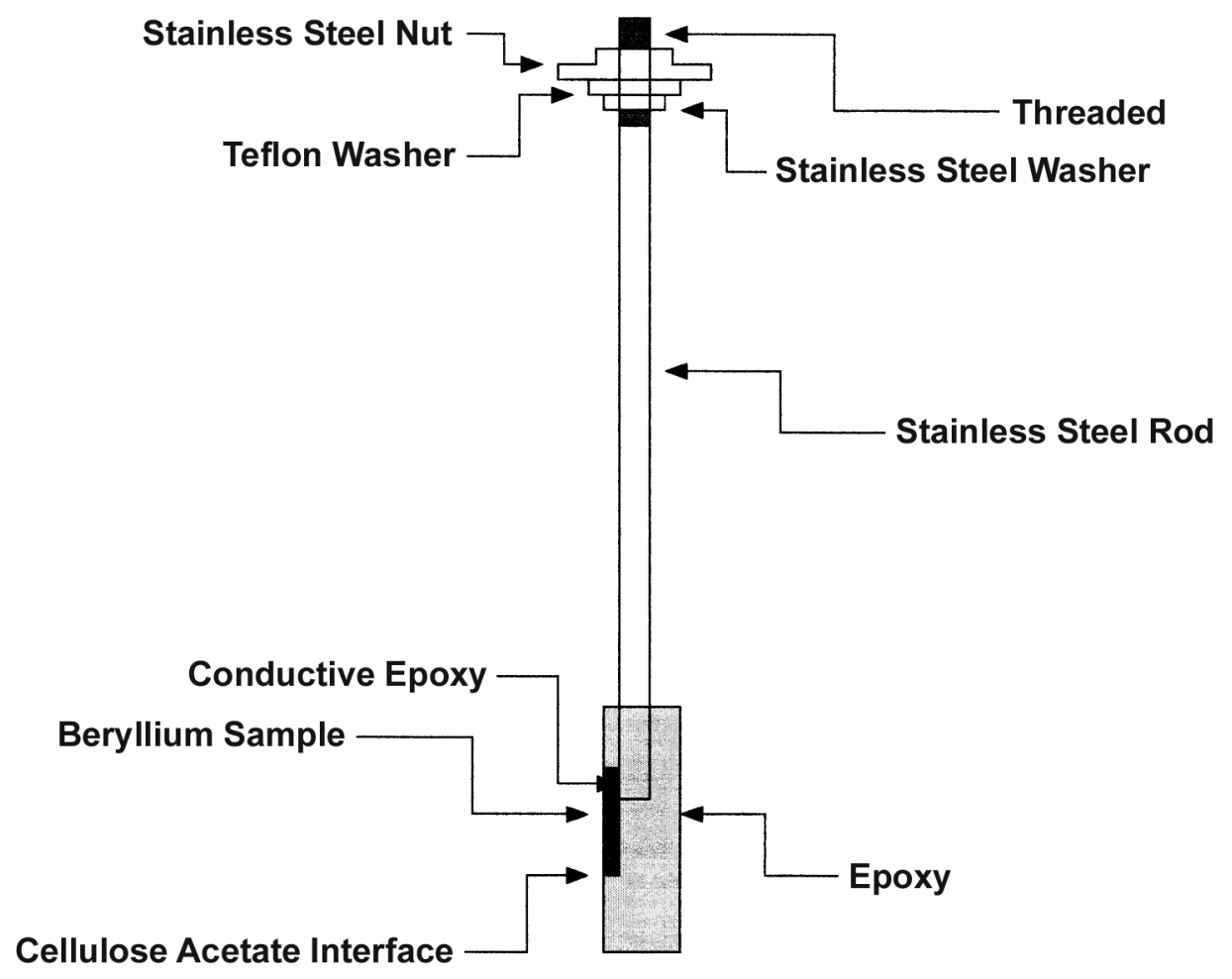

Figure 2. Custom made beryllium single crystal holder.

\section{History/Preparation of Beryllium Specimens}

Polycrystalline specimens were cut from tensile bars into disks measuring 5/8" dia x 1/8" thick. The tensile bars were cut from a beryllium metal cylinder, 6.00" dia x 11.00" long, several years ago. The original powder pressed beryllium metal rod was fabricated at Kawecki Berylco 
Industries, Inc. As shown in Figure 3, the polycrystalline beryllium had an average grain size of $11.2 \mu \mathrm{m}-11.5 \mu \mathrm{m}$, with a maximum grain size of $35 \mu \mathrm{m}$ to $36 \mu \mathrm{m}$. The chemical analysis is shown in Table 1. Corrosion wafers were given a one-sided metallographic polish on a sub-micron grit wheel.
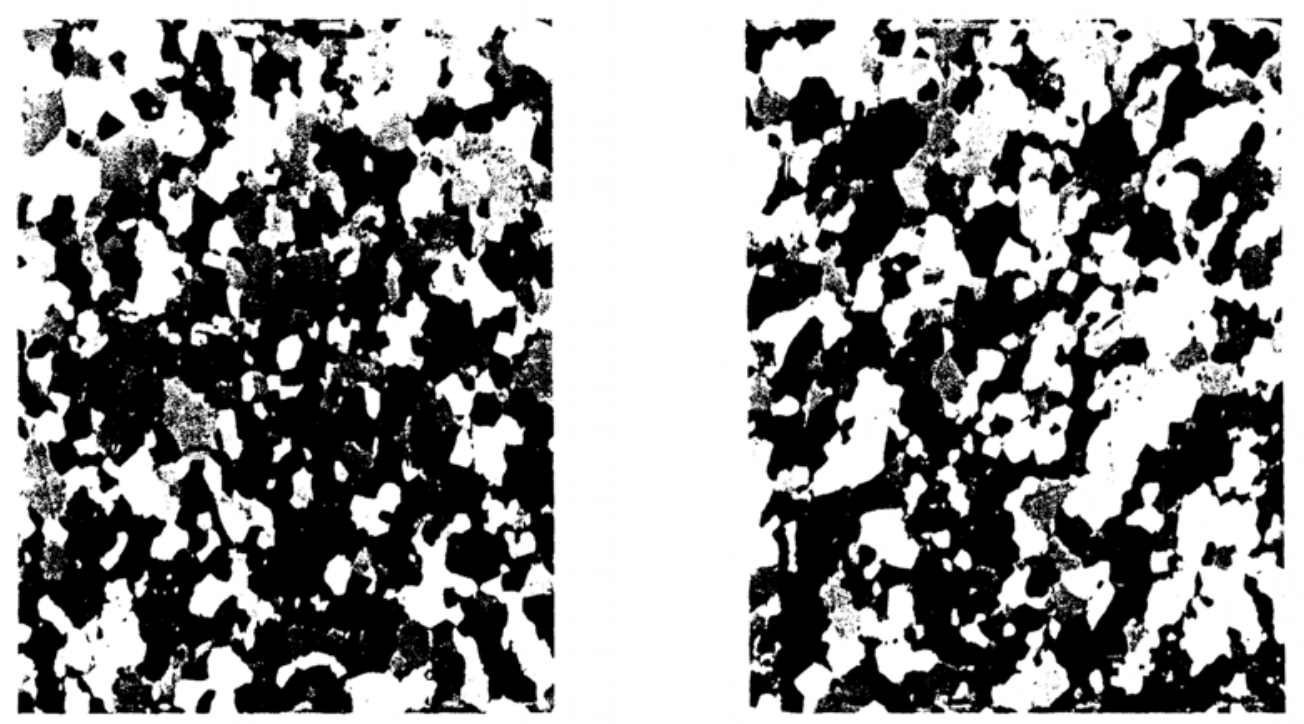

Figure 3. Photomicrographs of the of polycrystalline beryllium specimens. $(11.2-11.5 \mu \mathrm{m}$ average and $35-36 \mu \mathrm{m}$ maximum grain size)

The high-purity, single crystal beryllium was made from electrolytically refined beryllium, which was subsequently vacuum cast and extruded into a $1.8 \mathrm{~mm}$ round bar. The bar was subjected to a minimum of three floating zone passes to further remove impurities and produce the single crystal. The single crystal was one specimen of several which were obtained from the Franklin Institute Research Laboratory (FIRL) many years ago. FIRL had developed superior techniques to purify and grow beryllium single crystals. The impurity levels of this specific single crystal were not determined by chemical analysis; however, it is known that the beryllium made at FIRL by these processes usually contain less than approximately 20 atomic ppm of impurities. ${ }^{1}$ The main impurities present are carbon, iron, and oxygen.

The specific crystal selected was large enough to extract several corrosion specimens with different crystallographic orientations. While the impurities content was very low, it had been alloyed with approximately 0.3 atomic percent copper. The copper was in solid solution, and no beryllium-copper phases were observed. We do not believe that this small level of copper in solid solution would have a significant effect on the corrosion behavior and, as to be discussed in detail, this was supported by the similarities between the single crystals and the polycrystalline material.

\footnotetext{
${ }^{1}$ R.F. Bunshaw and R.S. Juntz, "Purification of Beryllium by Crucible-Free Vacuum Melting and Distillation Processes," Beryllium Technology, 1966, ed. Schetky and Johnson, Gordon and Breach Science Publishers, Inc., NY.
} 


\begin{tabular}{cccc} 
Dimension & Composition $\%$ & & Density \\
\hline $5 / 8 " \times 1 / 8 "$ & Be Assay & 98.4 & $1.854 \mathrm{~g} / \mathrm{cc}$ \\
& $\mathrm{BeO}$ & 1.19 & \\
$\mathrm{C}$ & 0.05 & \\
$\mathrm{Fe}$ & 0.095 & 0.026 \\
$\mathrm{Al}$ & 0.008 \\
$\mathrm{Mg}$ & 0.022 \\
$\mathrm{Si}$ & 0.016 \\
$\mathrm{Ni}$ & 0.005 \\
$\mathrm{Cr}$ & 0.004 \\
$\mathrm{Mn}$ & 0.007 \\
$\mathrm{Cu}$ & 0.003 \\
$\mathrm{Ti}$ & $<0.015$ \\
$\mathrm{Si}$ & 0.006 \\
$\mathrm{U}$ &
\end{tabular}

Table 1. Polycrystalline Be impurities

Specimens were machined to specific planes, using the back reflection Laue technique. The surface of the basal plane specimen was cut and polished to within $4.5^{\circ}$ of the (0001) plane, the surface of the type I prism plane specimen to within $0.5^{\circ}$ of the (1010) plane, and the surface of the type II prism plane specimen to within $4.1^{\circ}$ of the (1120) plane. The final dimensions of the single crystals to be corrosion tested were approximately $1.5 \mathrm{~cm} \times 1.5 \mathrm{~cm} \times 0.3 \mathrm{~cm}$, yielding 2.25 square centimeters surface area exposed to solution.

\section{Electrochemical Polarization and Pitting Studies of Polycrystalline Samples}

The polarization studies of the beryllium single crystals were conducted at $25^{\circ} \mathrm{C}$ in a single compartment glass cell, with two graphite counter electrodes. Polycrystalline samples were run in varying $\mathrm{NaCl}$ solutions and varying $\mathrm{pH}$ solutions. This polycrystalline experimental matrix is depicted in Figure 4. All three single crystals were run in a $0.01 \mathrm{M} \mathrm{NaCl}$ solution with a nominal $\mathrm{pH}$ of 7. Previous work with beryllium polycrystalline samples indicated that this solution would provide a reasonable level of corrosion. Reagent-grade chemicals and deionized water were used for all runs. The $\mathrm{pH}$ was adjusted using highly diluted $\mathrm{HCl}$ or $\mathrm{NaOH}$ and measured using an Orion brand, model 520A pH meter. Bubbling nitrogen gas through the solution for 30 minutes prior to the tests deoxygenated solutions. The potential of the beryllium crystals was measured in reference to a silver/silver chloride reference electrode. 
Cyclic polarization test was used to study the corrosive behavior of the beryllium specimens. In electrochemical corrosion theory, one of the tools available to determine the susceptibility of a material to corrosion is the cyclic polarization curve. A typical cyclic polarization curve of 316 stainless steel is shown in Figure 5. Using a potentiostat, the potential is controlled to a very precise degree. When running a cyclic polarization test, the computer will start at a predefined potential. The potential is programmed to begin at $100 \mathrm{mV}$ below the open circuit potential. The potentiostat then will scan potentials in the more positive direction while recording the current response; in our case at $0.167 \mathrm{mV} / \mathrm{s}$. Once a programmed current threshold is reached $(0.1 \mathrm{~mA})$, the potentiostat reverses the potential scan and sweeps back to the open circuit potential. The cyclic polarization curve is simply the potential on the y-axis, and the current response on the $\mathrm{x}$ axis. The shape of this curve along with the placement of critical points reveals much in the way of a material's inherent properties, along with its ability to withstand certain aqueous environments.

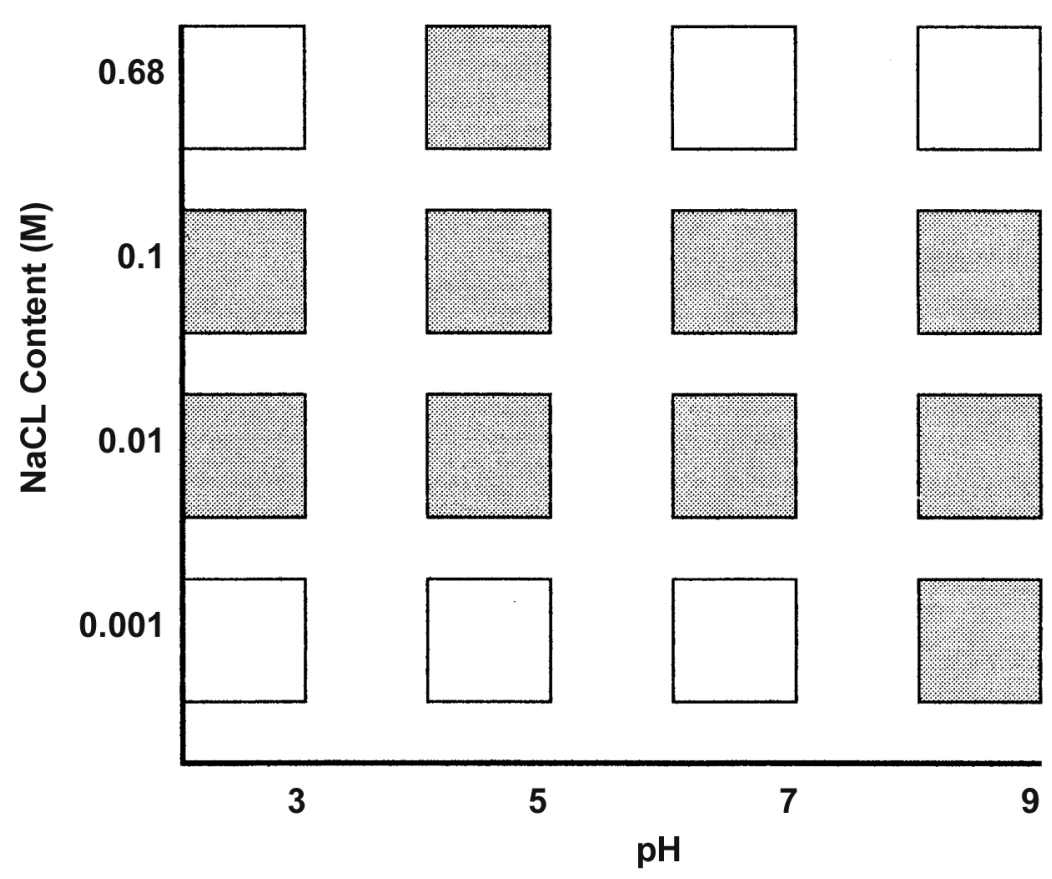

Figure 4. Experimental matrix of polycrystalline samples. Shaded squares indicate actual runs. 
$316 \mathrm{SS}$ in $0.001 \mathrm{M} \mathrm{NaCl}$, pH 7

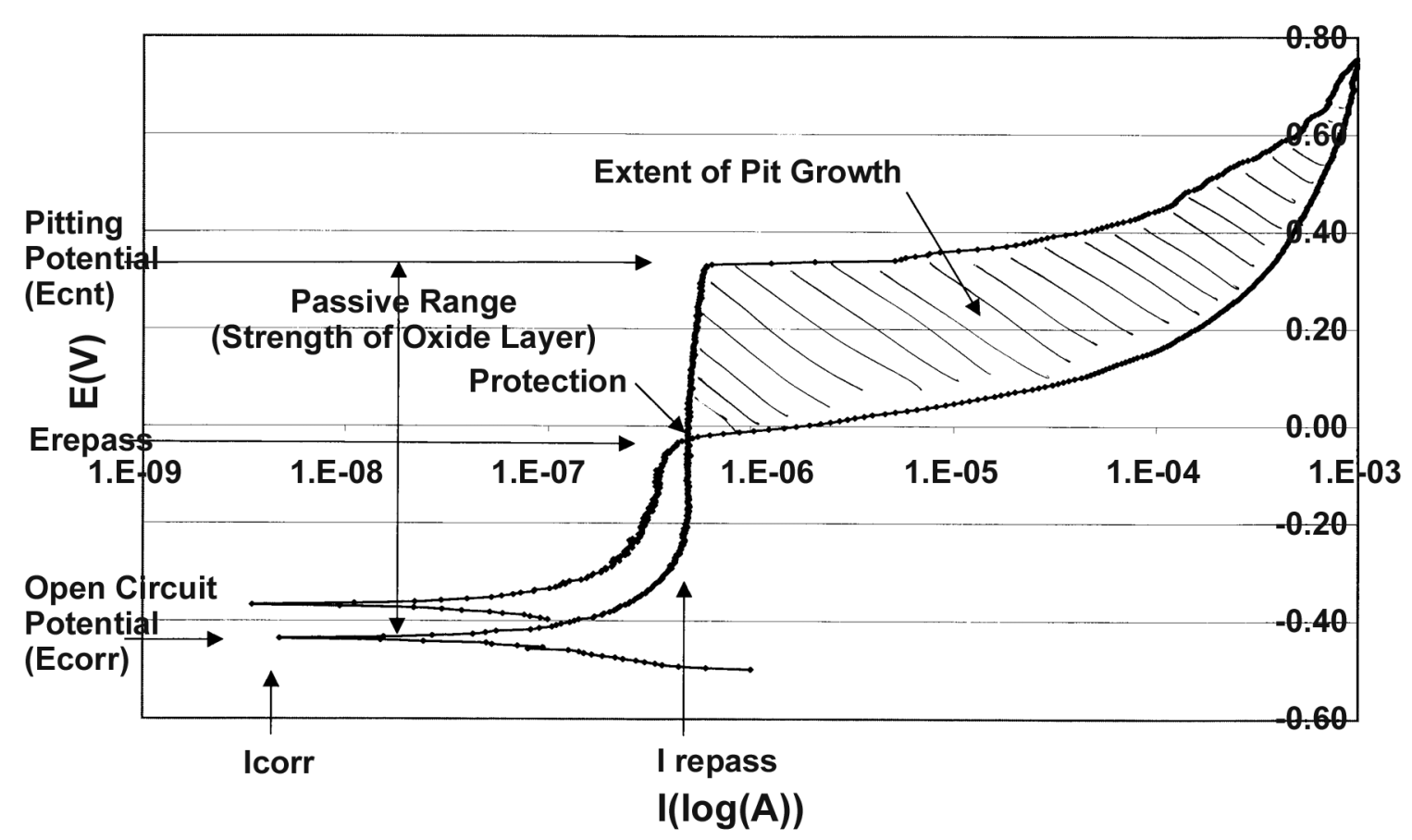

Figure 5. Sample cyclic polarization graph run on 316 stainless steel.

The open circuit potential is the potential difference between the electrode and the reference electrode once a steady state condition is reached, before polarization begins. In our studies, the beryllium specimens were immersed in solution one hour prior to polarization. Open circuit potential is a function of the material, and to a lesser degree the environment surrounding the material. Its value is as a benchmark, from which other critical points can be measured. As the forward scan begins, a potential increase is accompanied by a small current increase, and a large positive slope is recorded on the graph. This area is known as the passive range. The passive range is caused by the breakdown of the oxide layer on the material of interest. The height of the passive range is an indication of the adherence and thickness, or the overall strength of the material's inherent oxide film. The localized breakdown of the oxide film is depicted on the curve by an abrupt current increase as the applied potential continues to increase. At this point pitting corrosion is occurring. Once the current threshold is reached, the reverse scan begins in the more negative direction. The size of the hysteresis, or the degree from which the reverse scan deviates from the forward scan, is an indication of the pit growth which has occurred on the material. It should be noted that this hysteresis has value in qualitatively comparing samples, run under the same conditions, but has little value in formulating any sort of quantitative analysis of pit growth.

The point on the curve where the reverse scan intersects the forward scan is sometimes referred to as the protection point, or $\mathrm{E}_{\text {repass }}$ on the $\mathrm{y}$-axis and $\mathrm{I}_{\text {repass }}$ of the $\mathrm{x}$-axis. If a steady potential is applied above $\mathrm{E}_{\text {repass}}$, pitting corrosion can be initiated, but if a steady potential is applied below $\mathrm{E}_{\text {repass, }}$, no new pits will be initiated, but old ones will continue to corrode. If a polished, clean specimen receives a potential below $\mathrm{E}_{\text {repass }}$, no corrosion will occur, but if this specimen receives a potential above $\mathrm{E}_{\text {repass }}$, corrosion will occur. 
Corrosion-resistant materials, like 316 stainless steel or C22 (a nickel-based alloy), would display a relatively large passive range and a small hysteresis compared to a more reactive material like copper. Also, the electrolyte or solution that the specimen is immersed in will contribute to the shape and placement of critical points of the cyclic polarization curve. Whereas, C22 might display good corrosion resistance (i.e., large passive range) and small hysteresis in a $\mathrm{NaCl}$ electrolyte solution, the same material may show poor corrosion resistance in a mild acidic electrolyte solution.

\section{Pit Morphology}

All samples were examined using a Lieca brand, model MZ12, optical microscope before and after being exposed to cyclic polarization tests. A representative number of polycrystalline samples were examined using conventional scanning electron microscopy techniques before corrosion, while all were examined after corrosion. All single crystal samples were examined using these same SEM techniques before and after corrosion, at magnifications of 100x, 1000x, 2000x, $5000 x$, or other magnifications deemed necessary to reveal interesting features.

\section{Results/Discussion}

As a precursor to beryllium experiments, experimental technique and apparatus confirmation were ensured by completion of ASTM G-5 test. Results are shown in Figure 6. Also, many additional potentiodynamic runs in accord to ASTM G-61 test were run on 316 stainless steel specimens of the same dimensions under the same conditions to further ensure experimental technique and provide a basis for comparison. Figure 7 shows a stainless steel and polycrystalline beryllium cyclic polarization test on the same axis to aid in comparison.

\section{Type $430 \mathrm{SS}$ in $1 \mathrm{~N} \mathrm{H}_{2} \mathrm{SO}_{4}, 30^{\circ} \mathrm{C}$}

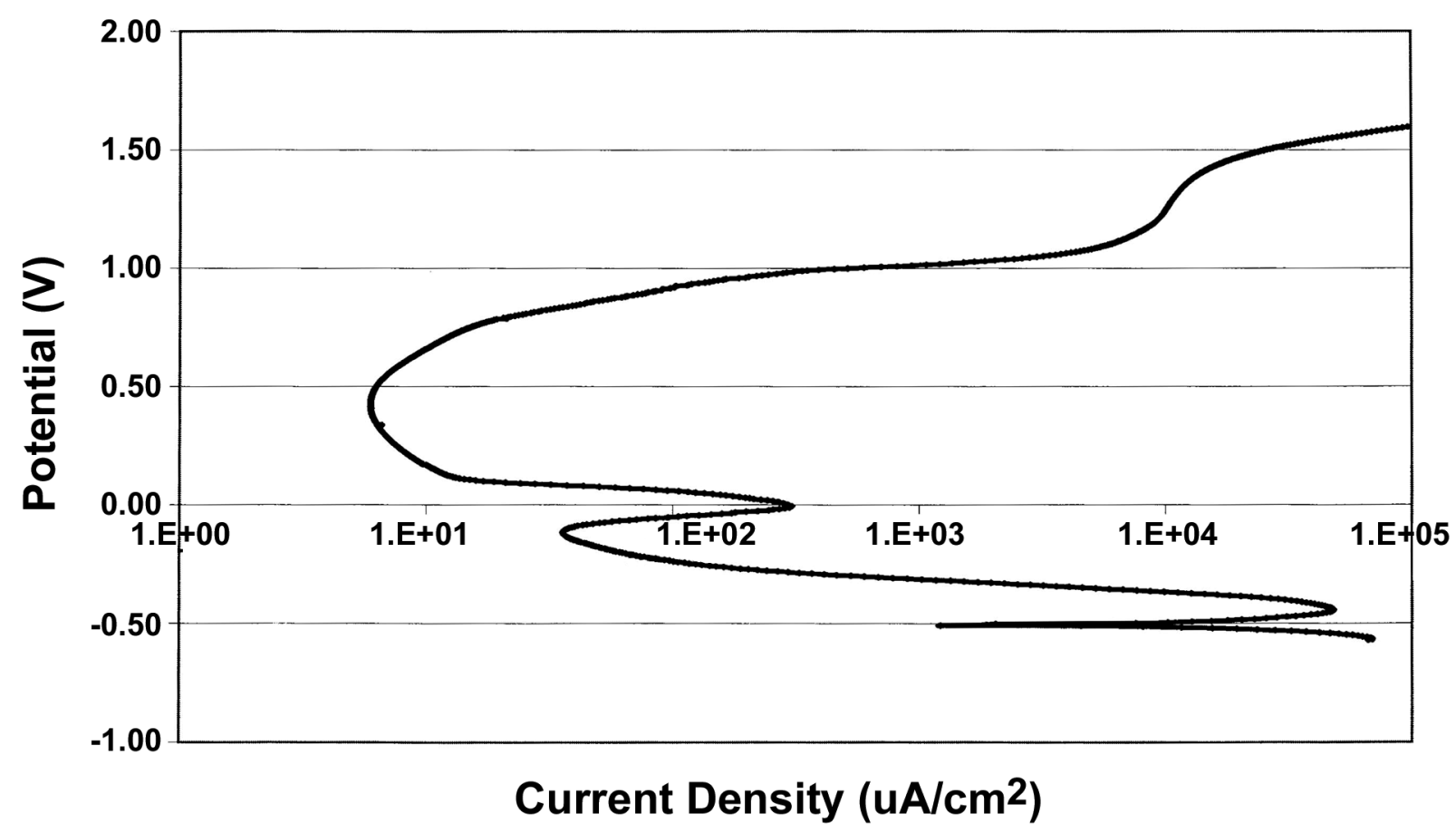

Figure 6. ASTM G-5 confirmation test. 


\section{SS and $\mathrm{Be}$ in $0.01 \mathrm{M} \mathrm{NaCl}, \mathrm{pH} 7$}

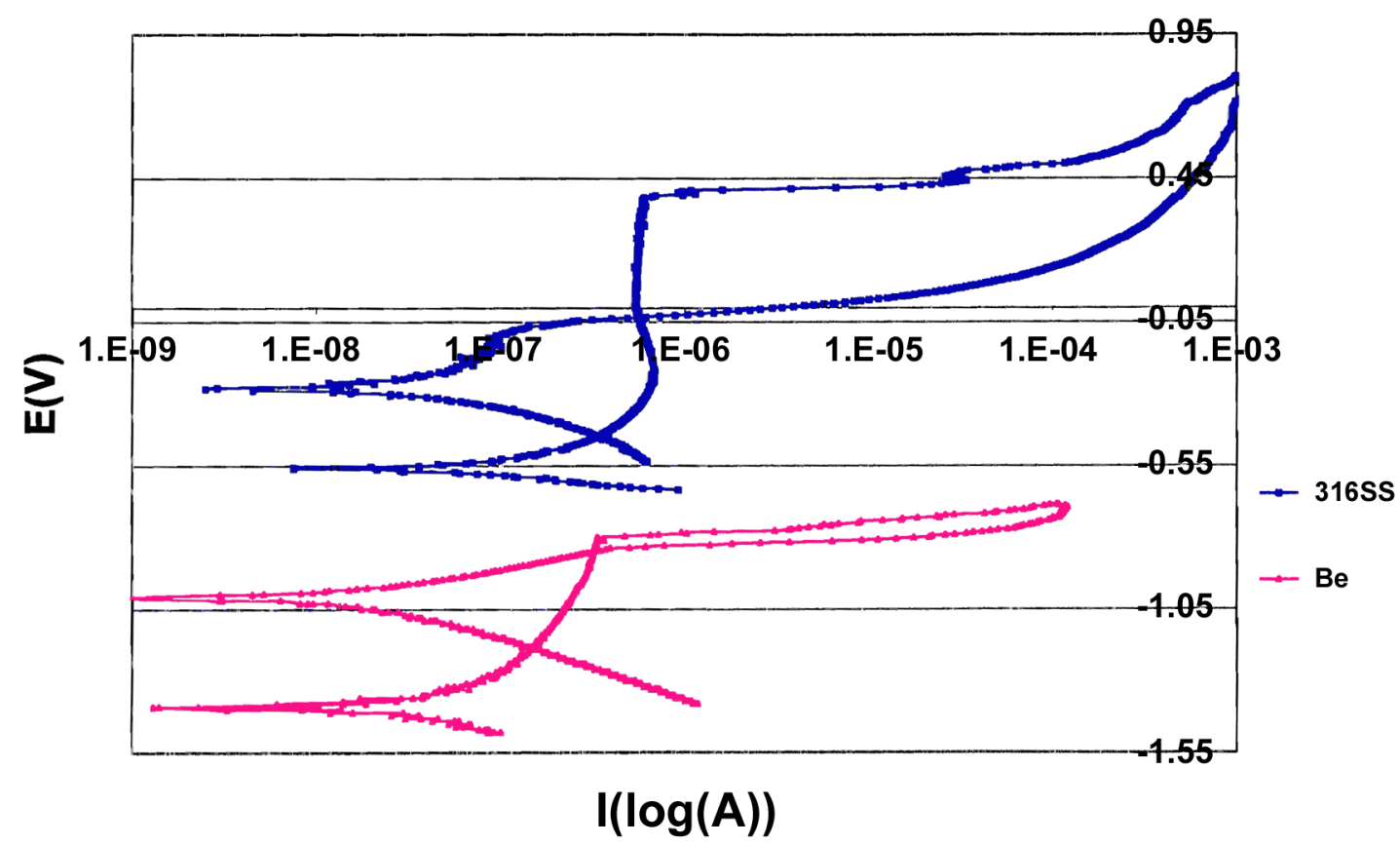

Figure 7. $316 \mathrm{SS}$ and Be cyclic polarization with same experimental conditions.

Varying the $\mathrm{pH}$ and $\mathrm{NaCl}$ concentration of the electrolyte solution has significant effects on the shapes of the cyclic polarization curves. Figure 8 and 9 show cyclic polarization curves for $0.1 \mathrm{M}$ and $0.01 \mathrm{M} \mathrm{NaCl}$ concentrations of varying $\mathrm{pH}$, respectively.

\section{$\mathrm{Be}$ in Varying $\mathrm{pH}, 0.1 \mathrm{M} \mathrm{NaCl}$}

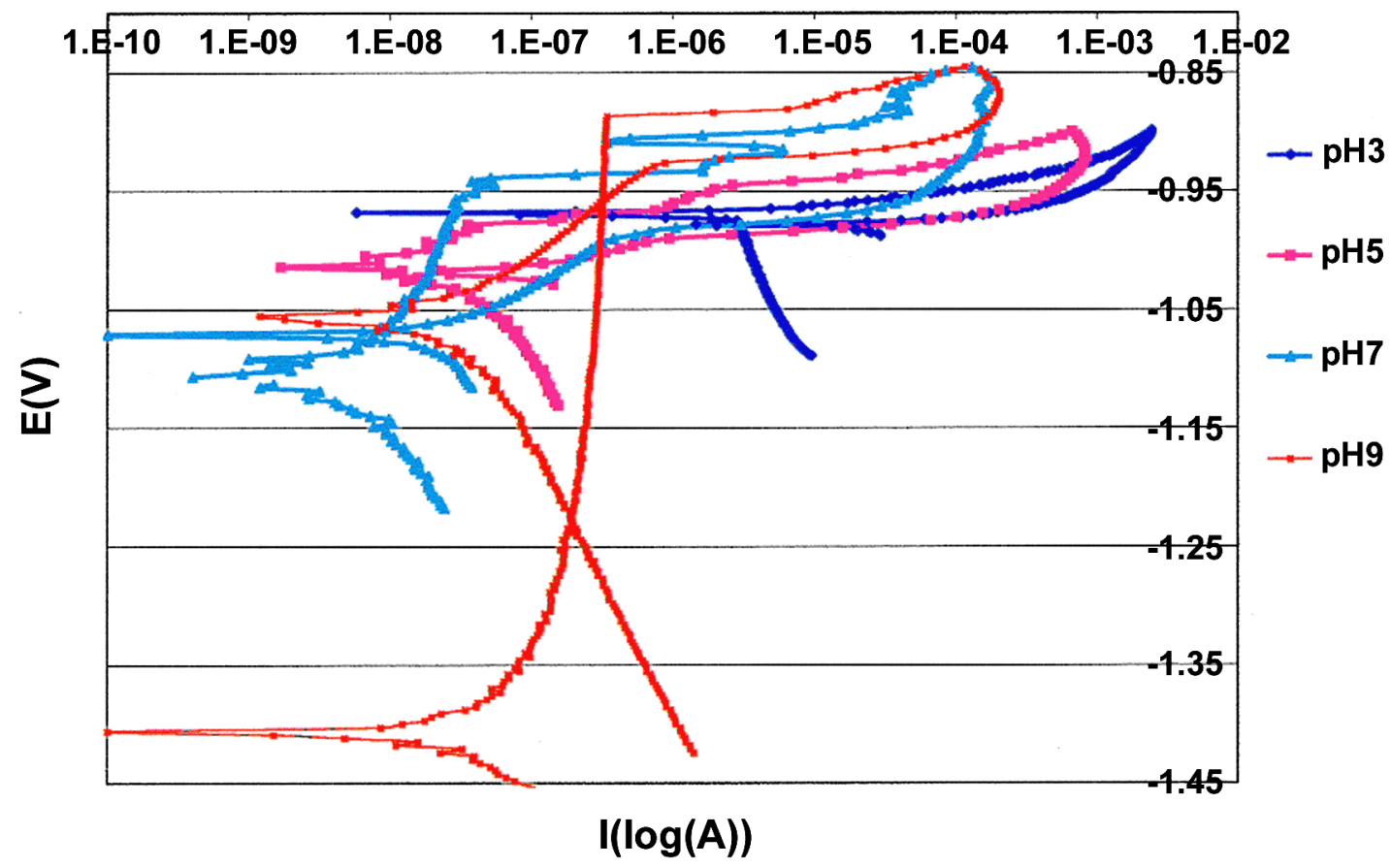

Figure 8. Beryllium polycrystalline samples in $0.1 \mathrm{M} \mathrm{NaCl}$ of varying $\mathrm{pH}$. 


\section{Be in Varying $\mathrm{pH}, 0.01 \mathrm{M} \mathrm{NaCl}$}

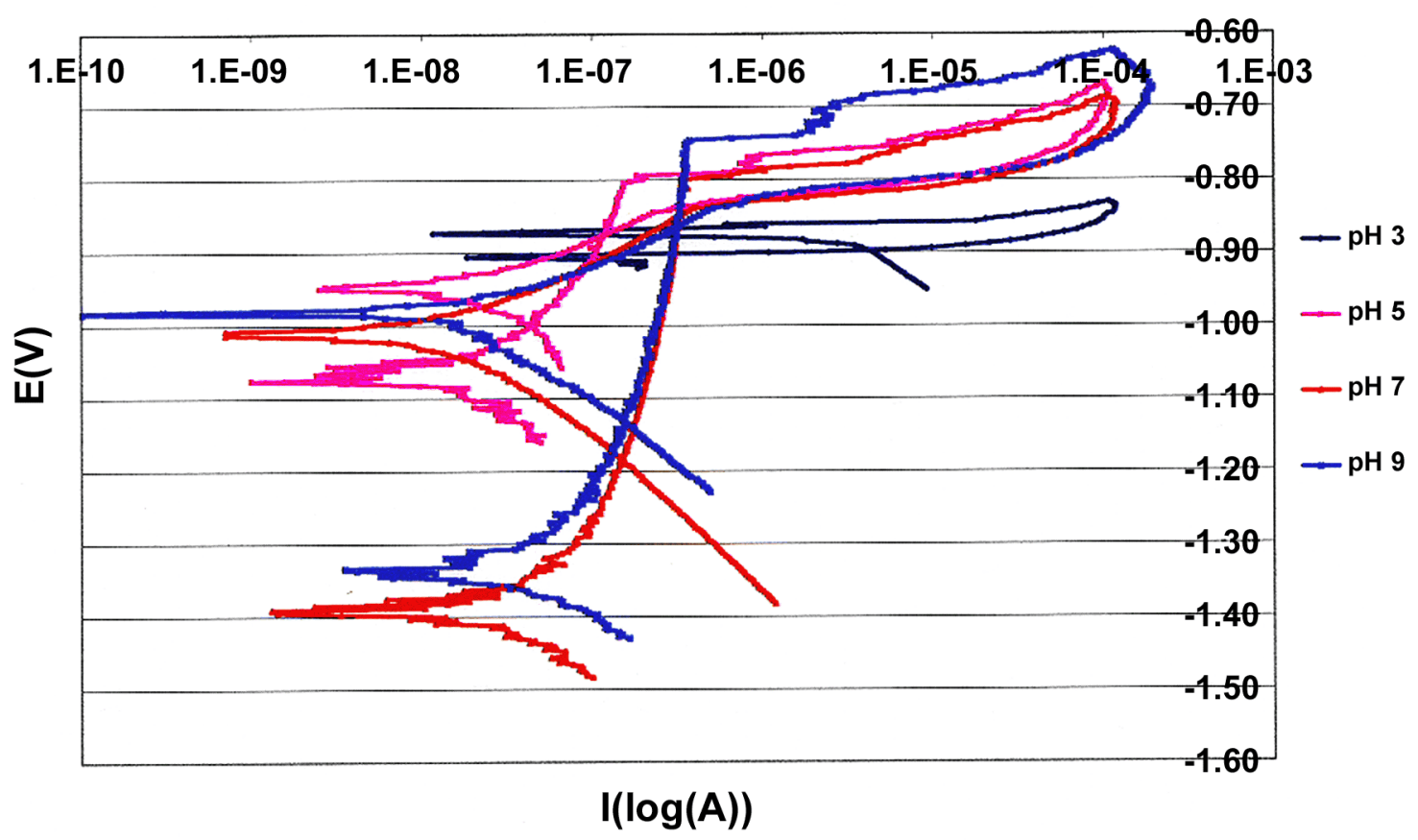

Figure 9. Beryllium polycrystalline samples in $0.01 \mathrm{M} \mathrm{NaCl}$ of varying $\mathrm{pH}$.

While open circuit potential (Ecorr) is inversely proportional to $\mathrm{pH}$, pitting potential (Ecrit) and the size of the passive range ( $\mid$ Ecorr - Ecrit $\mid$ ) is directly proportional to $\mathrm{pH}$. These correlations are shown in Figures 10 and 11.

Although a wide range of solution concentrations was not run, it is apparent that solution $\mathrm{pH}$ had a much larger effect on the corrosion of the polycrystalline beryllium than chloride concentration. Figure 12 shows cyclic polarization curves for varying concentrations of chloride ions, with a nominal $\mathrm{pH}$ of 9. 
Beryllium Analysis, $0.1 \mathrm{M} \mathrm{NaCl}$

\begin{tabular}{cccccc} 
pH & Passive Range & pH & O.C.P. (V) & pH & P.P. (V) \\
\hline 9 & 0.523 & 9 & -1.41 & 9 & -0.887 \\
7 & 0.168 & 7 & -1.11 & 7 & -0.942 \\
5 & 0.032 & 5 & -1.01 & 5 & -0.978 \\
3 & 0 & 3 & -0.968 & 3 & -0.968
\end{tabular}

pH vs Passive Range, $0.1 \mathrm{M} \mathrm{NaCl}$

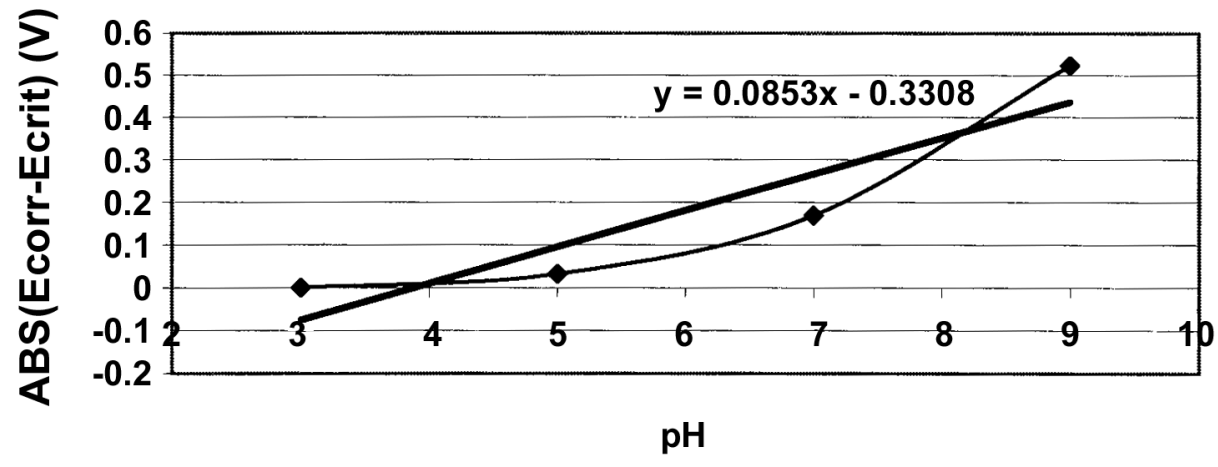

pH vs Open Circuit Potential, 0.1M NaCl

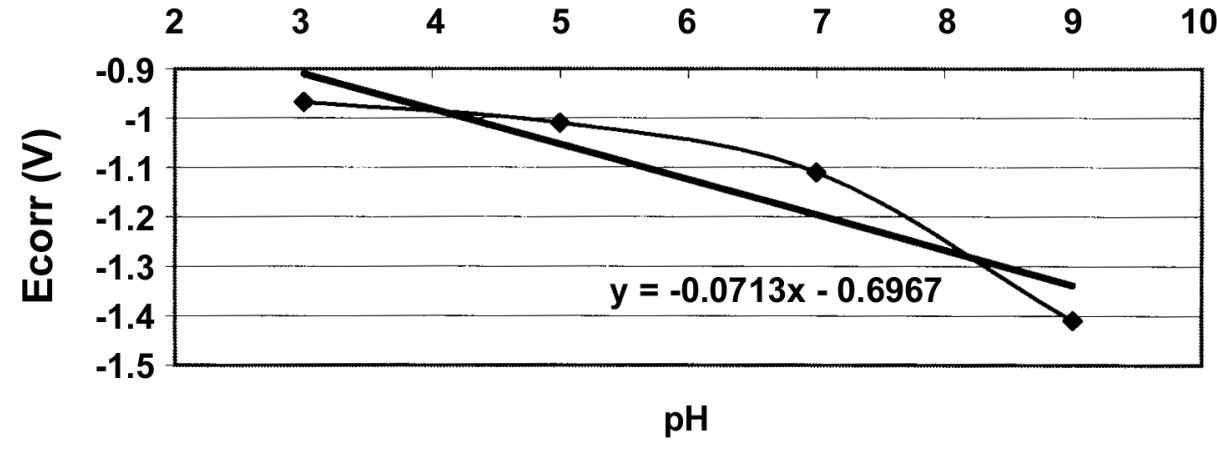

pH vs Pitting Potential, 0.1M NaCl

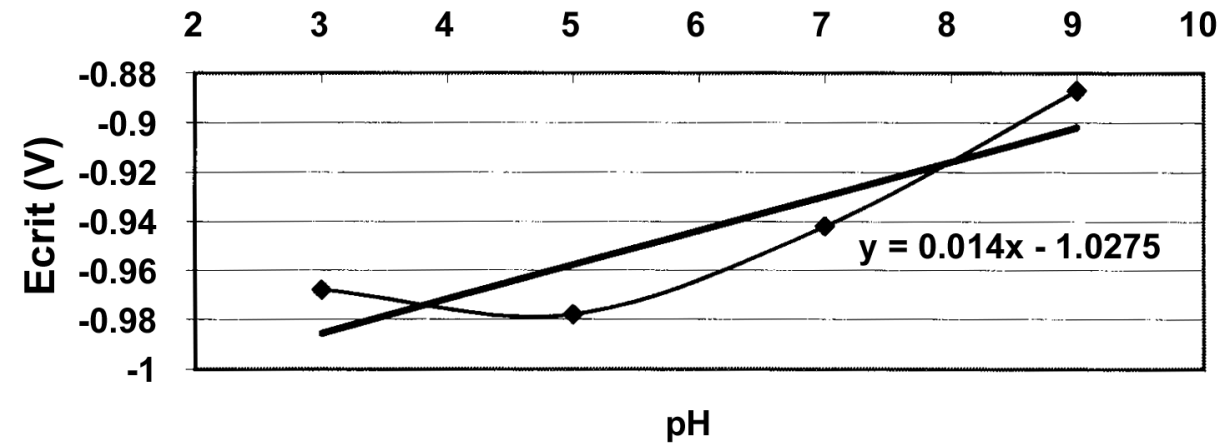

Figure 10. Analysis of $0.1 \mathrm{M} \mathrm{NaCl}$ cyclic polarization curves of varying $\mathrm{pH}$. 
Beryllium Analysis, $0.01 \mathrm{M} \mathrm{NaCl}$

\begin{tabular}{cccccc} 
pH & Passive Range & pH & O.C.P. (V) & pH & P.P. (V) \\
\hline 9 & 0.584 & 9 & -1.33 & 9 & -0.746 \\
7 & 0.596 & 7 & -1.39 & 7 & -0.794 \\
5 & 0.274 & 5 & -1.08 & 5 & -0.806 \\
3 & 0 & 3 & -0.873 & 3 & -0.873 \\
\hline
\end{tabular}
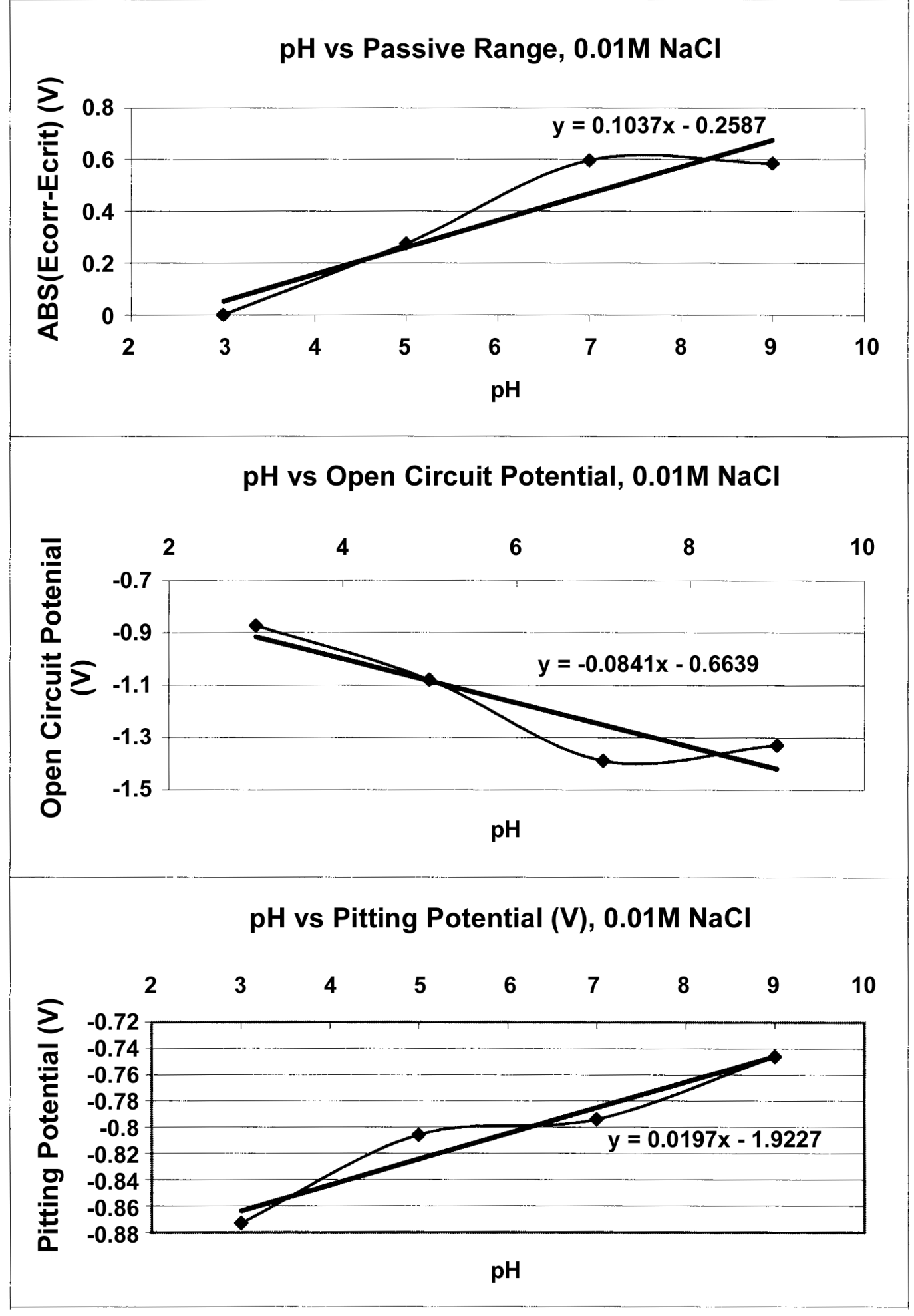

Figure 11. Analysis of $0.01 \mathrm{M} \mathrm{NaCl}$ cyclic polarization curves of varying $\mathrm{pH}$. 
Be in Varying $\mathrm{NaCl}$ Concentration, pH 9

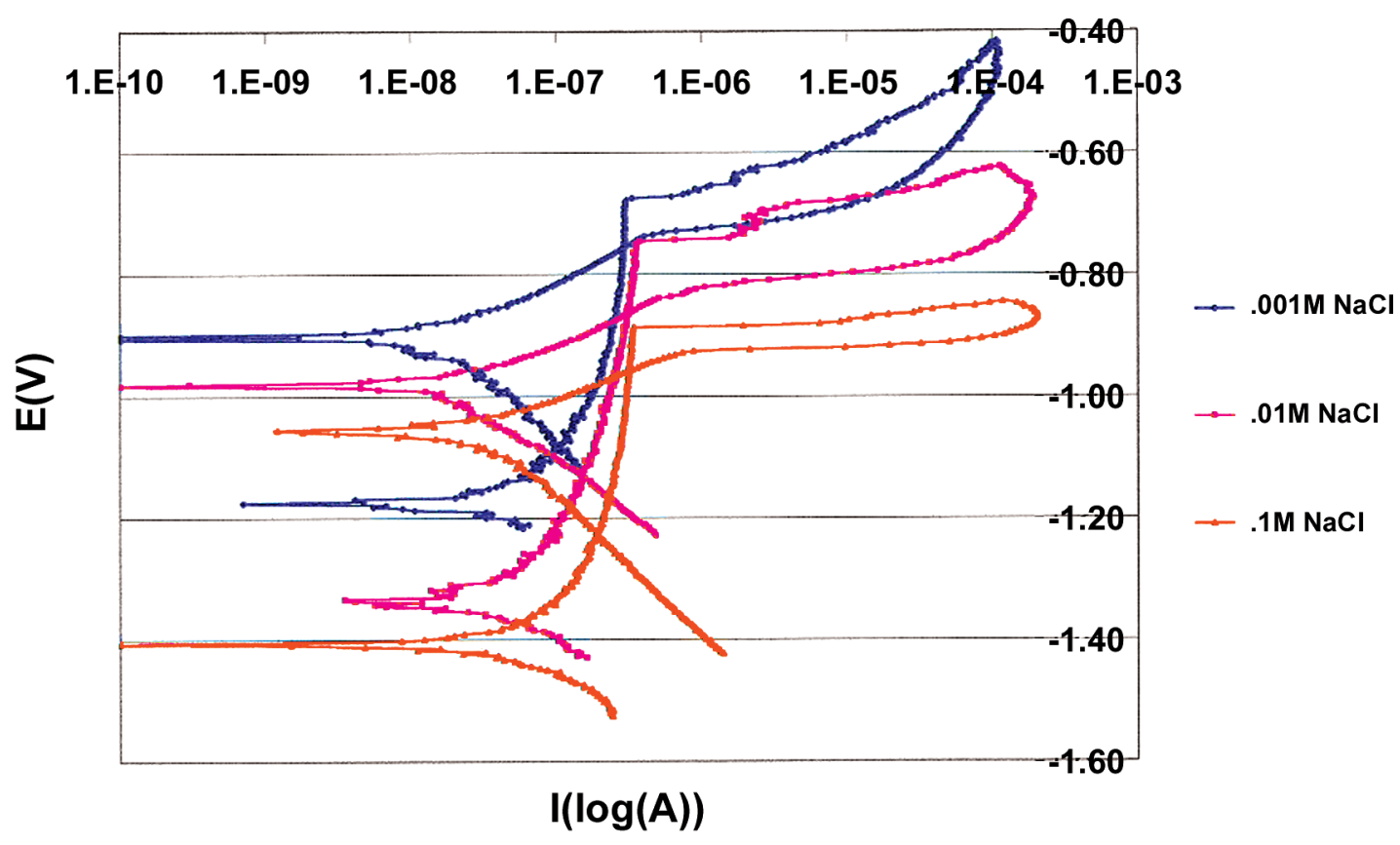

Figure 12. Cyclic polarization curves for varying concentrations, $\mathrm{pH} 9$.

Both $\mathrm{E}_{\text {corr }}$ and $\mathrm{E}_{\text {crit }}$ of beryllium polycrystalline specimens in varying concentrations of chloride ions displayed the same trends as in varying the $\mathrm{pH}$. Both were directly proportional. The size of the passive range varied insignificantly with changing chloride concentration. Size of the passive range or the ability of a solution to break down the oxide layer on the surface of polycrystalline beryllium appears to be a function of $\mathrm{pH}$, and not of chloride concentration. Figure 13 shows polycrystalline beryllium analysis of the cyclic polarization curves of varied chloride concentration at a nominal $\mathrm{pH}$ of 9 .

Our data generally agrees with LANL studies on polycrystalline beryllium corrosion behavior. ${ }^{2}$

\footnotetext{
2 "M.A. Hill, D.P. Butt, and R.S. Lillard, “The Passivity and Breakdown of Beryllium in Aqueous Solutions,” J. Electrochem Soc., Vol 145, No.8, August 1998.
} 
Beryllium Analysis, pH 9

\begin{tabular}{lccc} 
Conc & O.C.P.(V) & P.P.(V) & Passive Range (V) \\
\hline 0.001 & -1.18 & -0.675 & 0.505 \\
0.01 & -1.33 & -0.746 & 0.585 \\
0.1 & -1.41 & -0.887 & 0.59
\end{tabular}

Solution Molarity vs Open Circuit Potential

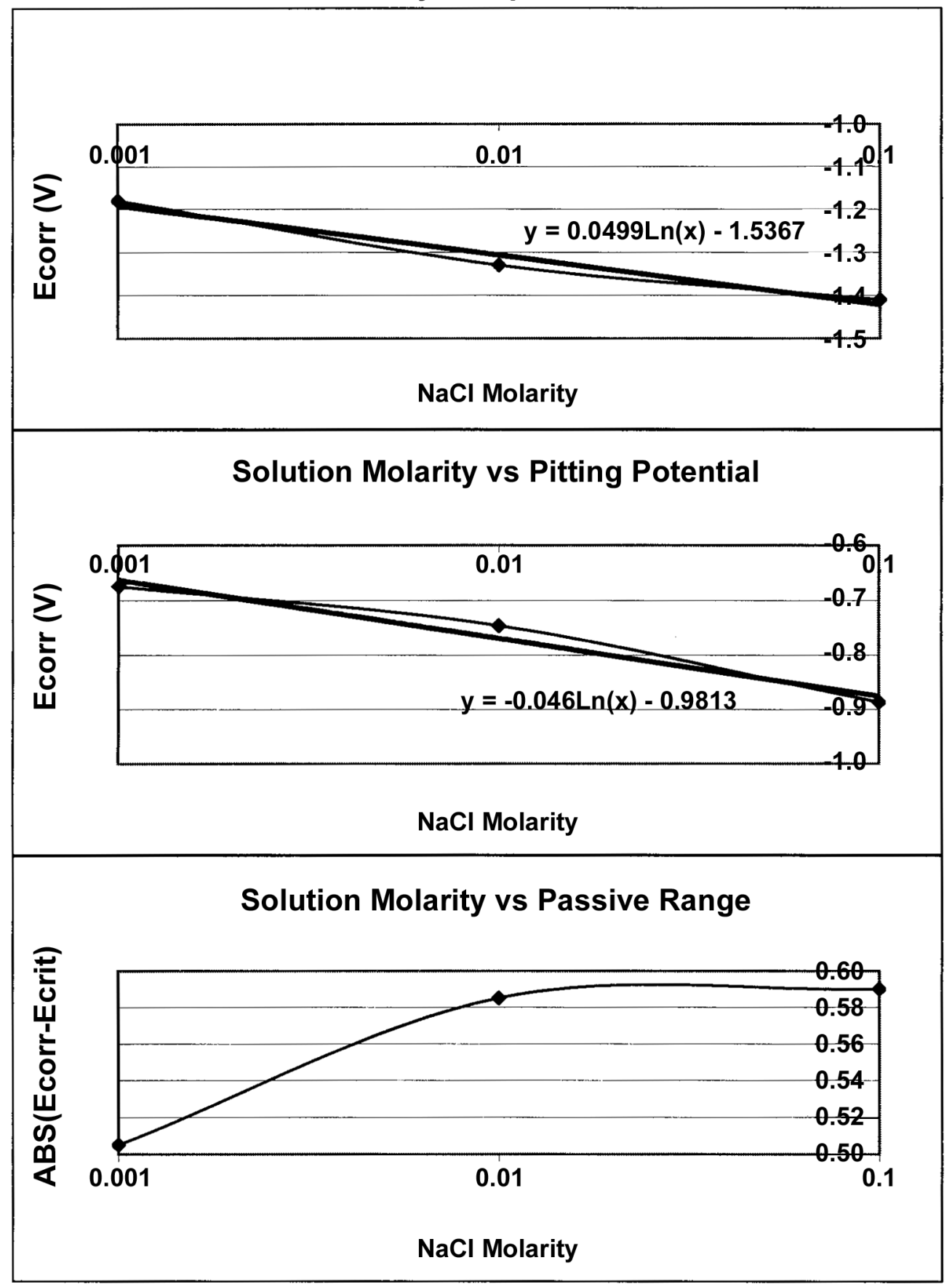

Figure 13. Polycrystalline analysis of cyclic polarization curves for varied chloride concentration, nominal pH 9. 


\section{Polycrystalline Pit Morphology}

After potentiodynamic polarization, polycrystalline specimens showed pit corrosion. Pits were wide and shallow in shape, whereas pits of $316 \mathrm{SS}$ exposed to the same experimental conditions showed deeper, more narrowed pits. Cross-sectional drawings of pits in both 316 SS and ploycrystalline beryllium are shown in Figure 14, and compared to a range of pit morphologies.
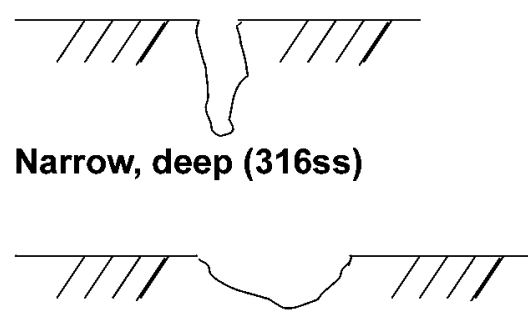

Wide, shallow (beryllium)

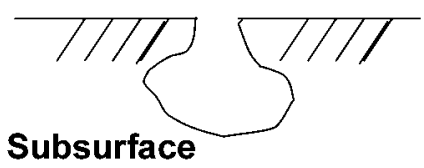

\section{Vertical (316ss)}
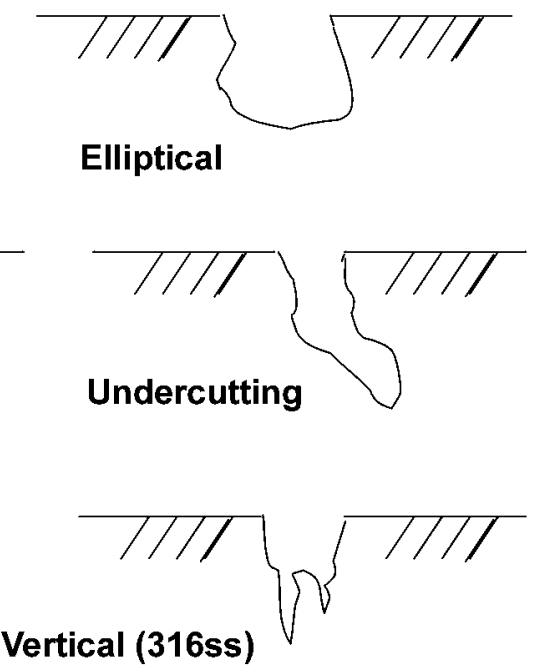

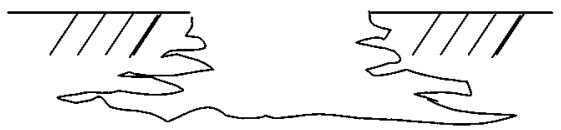

Horizontal

Figure 14. Cross sectional drawing of typical corrosion pits for a variety of metals.

Pits tended to be irregularly shaped with crystallographically oriented "fibers" or "trenches." Grain boundaries were seen where these fibers came together at different angles as shown in Figure 15.

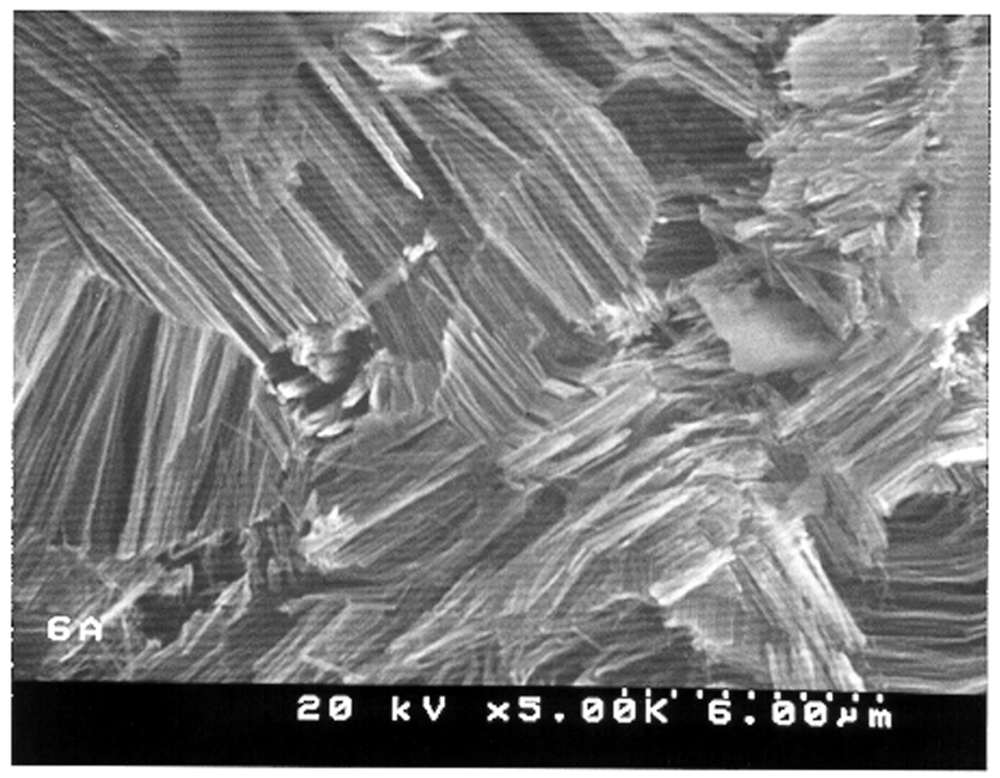

Figure 15. Crystallographically oriented fibers come together at different angles to form grain boundaries. 
Scanning electron micrographs suggested that pits began growth inside grains and were not intiated on grain boundaries. Pit growth continued as long as potentials were greater than Ecrit. Pits appeared to grow outwards until a grain boundary was encountered. The morphology of the pits appears to correspond to individual grains or small groups of grains. The corrosion appears to cease at grain boundaries, but not at all grain boundaries. This suggests that grain boundaries and other localized phenomena, such as impurities and inclusions, are not a major factor in corrosion; thus, this suggests that crystallographic orientation may be a significant factor in corrosion of beryllium. This is shown in Figure 16.

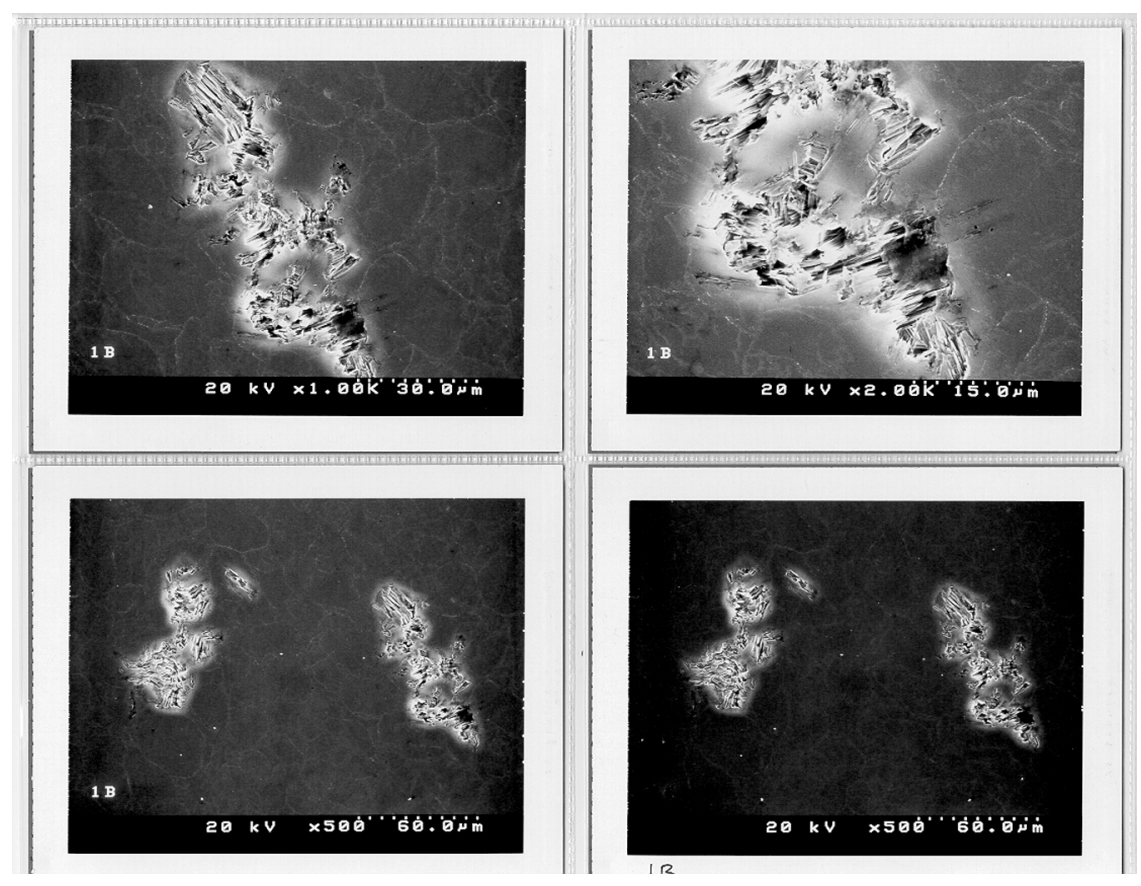

Figure 16. Corrosion initiated inside grains and continued outwards, filling the entire grain before expanding outside of the grain boundary.

Small single pits were not scattered randomly across specimen surfaces. Rather, multigrain pits would occur in specific locations, as shown in Figure 17. It is unclear whether this happened due to other causes such as oxide layer weakness/defects and inclusions; or surface defects such as large scratches; or by pits preferentially being initiated on certain grain orientations and then spreading beyond. If the latter were the case, one would expect to find only single grain pits of a certain crystallographic orientation to be present. This was not the case. 


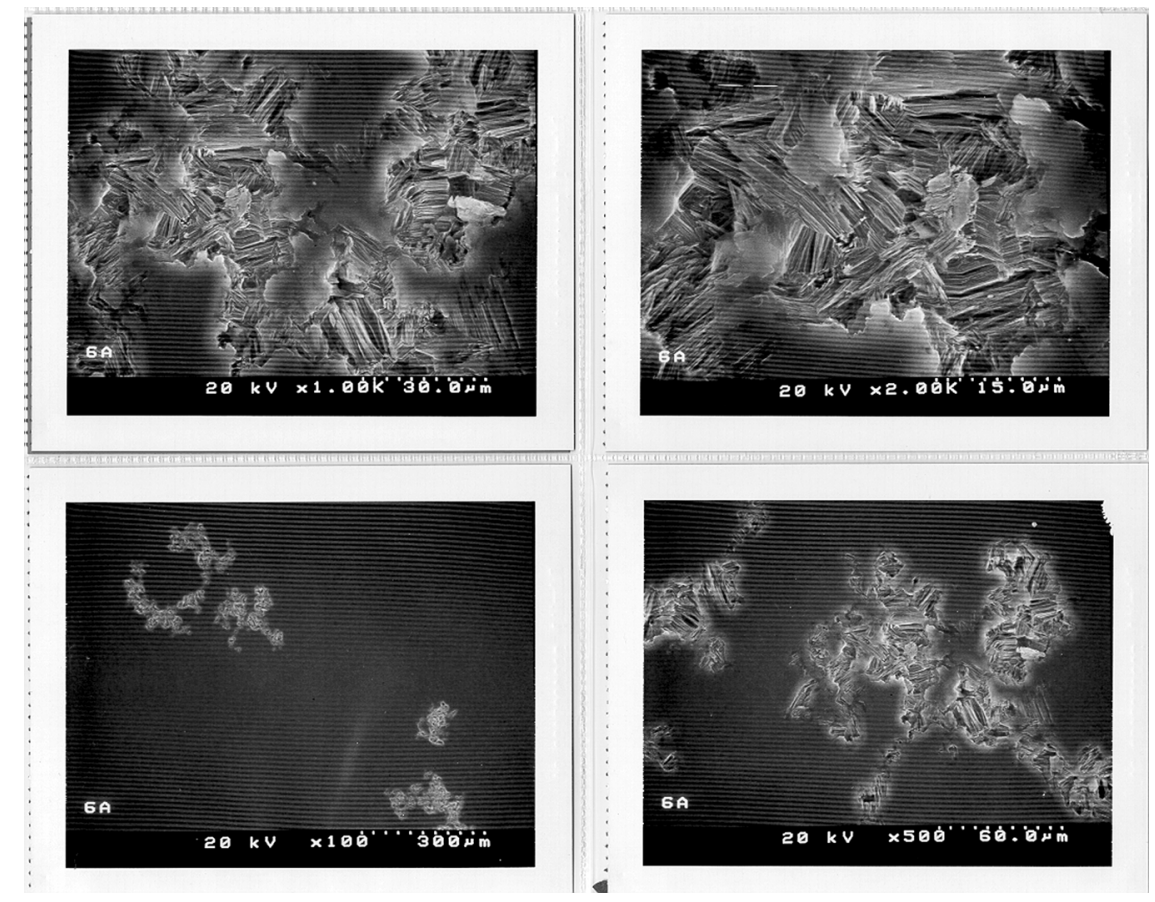

Figure 17. Corrosion pits are much larger than the maximum grain size of $36 \mu \mathrm{m}$, which suggests these pits cover multiple grains of differing crystallographic orientations.

\section{Single Crystal Results/Discussion}

Cyclic polarization curves of the three single crystal specimens displayed key dramatic differences as shown in Figure 18. This statement is consistent with LANL studies of polycrystalline beryllium studies. ${ }^{3}$ Open circuit potential was close to identical for the two prism planes, $-1.17 \mathrm{~V}$, and was significantly greater for the basal plane, $-0.927 \mathrm{~V}$.

\footnotetext{
3 "The Corrosion/Electrochemistry of Beryllium and Beryllium Weldments in Aqueous Chloride Environments," by Mary Ann Hill, Darryl P. Butt, and R. Scott Lillard
} 


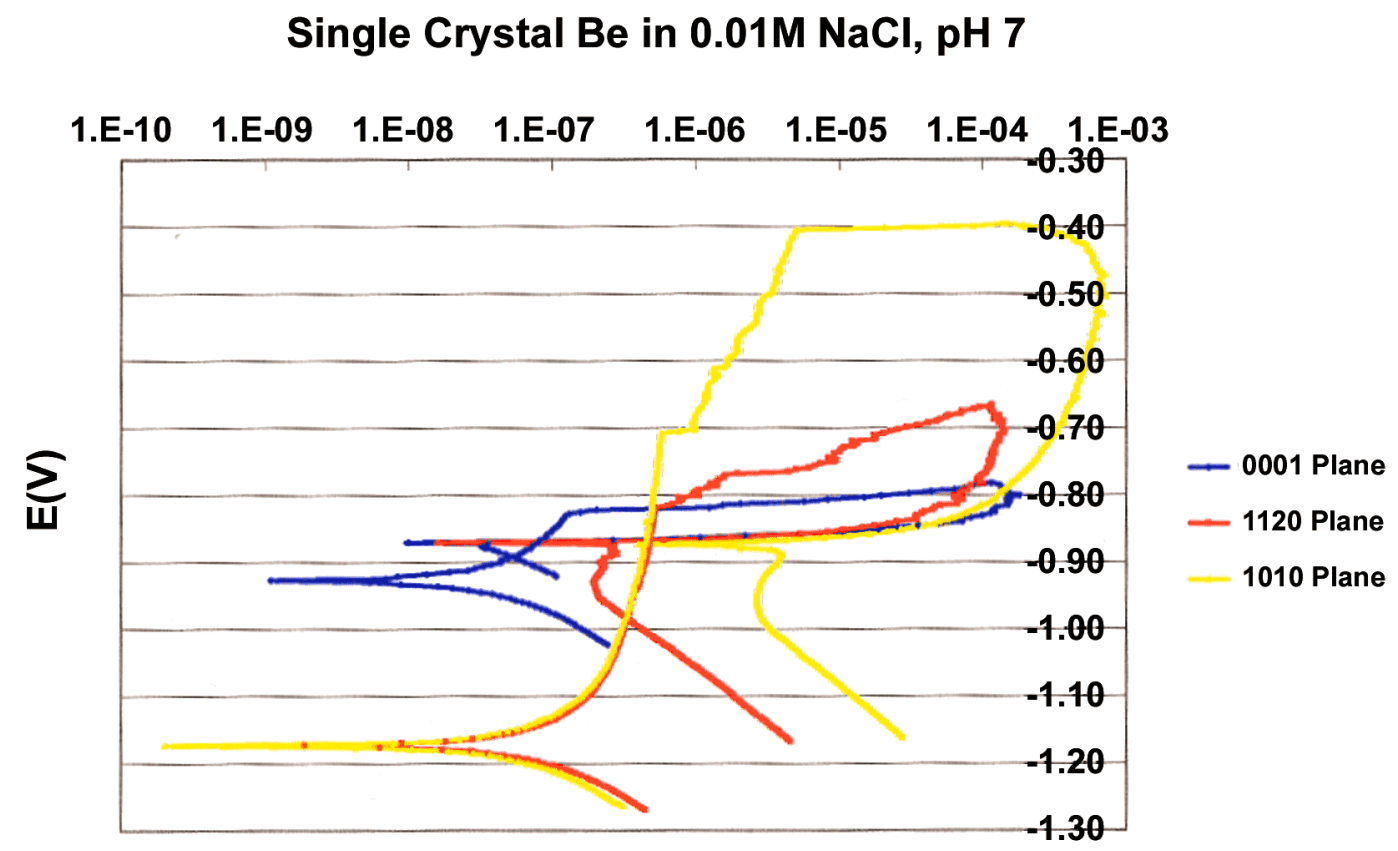

$1(\log (\mathrm{A}))$

Figure 18. Cyclic polarization curves for single crystals.

$\mathrm{I}_{\text {pass }}$ is nearly identical for the two prism planes and is significantly less for the basal plane, 4.34E-7 A and 1.07E-7 A, respectively.

The size of the passive range differs for all three planes, but the basal plane differs the most compared to the two prism planes. The 1010 prism plane has a passive range of $0.462 \mathrm{~V}$ while the 1120 prism plane's passive range is $0.363 \mathrm{~V}$, a $21 \%$ difference. The basal plane has a passive range of $0.102 \mathrm{~V}$, which deviates $75 \%$ from the average passive range of the two prism planes.

An interesting observation is that the $\mathrm{E}_{\text {repass }}$ is identical for all three crystals regardless of crystal orientation, $-0.864 \mathrm{~V}$.

It should be noted that a correlation exists between the size of the passive range and the planer densities. The planer atomic densities of the three beryllium crystal orientations appear to be inversely proportional to the passive range as shown in Figure 19. Figure 20 shows graphically that the relationship between the planer densities of the three crystal faces studied and the size of the passive range of the three crystal faces is similar. Passive range, being an indication of the oxide film strength, appears to be a function of crystal orientation. Further study of the electronic properties on the different crystal faces of single crystal beryllium is warranted.

In a comparative study on corrosion of single crystals of a different metal with the close packed hexagonal structure $(\mathrm{CPH})$, zinc, ${ }^{4}$ there were small differences in corrosion behavior as a function of crystallographic direction. This might be attributable to the atomic packing density on the particular planes. In this study on another HCP metal, beryllium, there were substantial differences in corrosion between the basal plane and the two prism planes. In zinc, there is

\footnotetext{
${ }^{4}$ R. Guo, F. Weinberg, and D. Tromans, "Pitting Corrosion of Passivated Zinc Monocrystals," Corrosion Science,
} Vol. 51, No. 5 (1995). 
metallic bonding in all crystallographic directions. In beryllium, there is metallic bonding parallel to the basal plane; i.e., facing the prism planes, but there is a tendency for covalent bonding in the (0001) direction. This corresponds to significant differences found in corrosion behavior.

\section{Be Single Crystal Analysis}

\begin{tabular}{cc} 
Planer Density & Ecorr - Epit \\
\hline 0.9069 & 0.102 \\
0.7854 & 0.363 \\
0.3927 & 0.462
\end{tabular}

\section{Planer Density vs Passive Range}

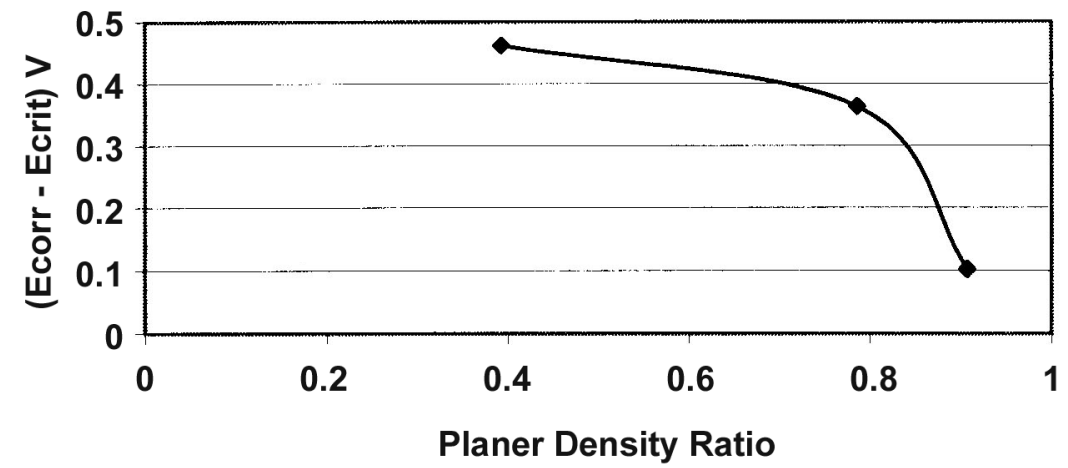

Figure 19. Relationship between planer densities and passive range. 


\section{ABS(Ecorr-Ecrit) of 3 Planes}

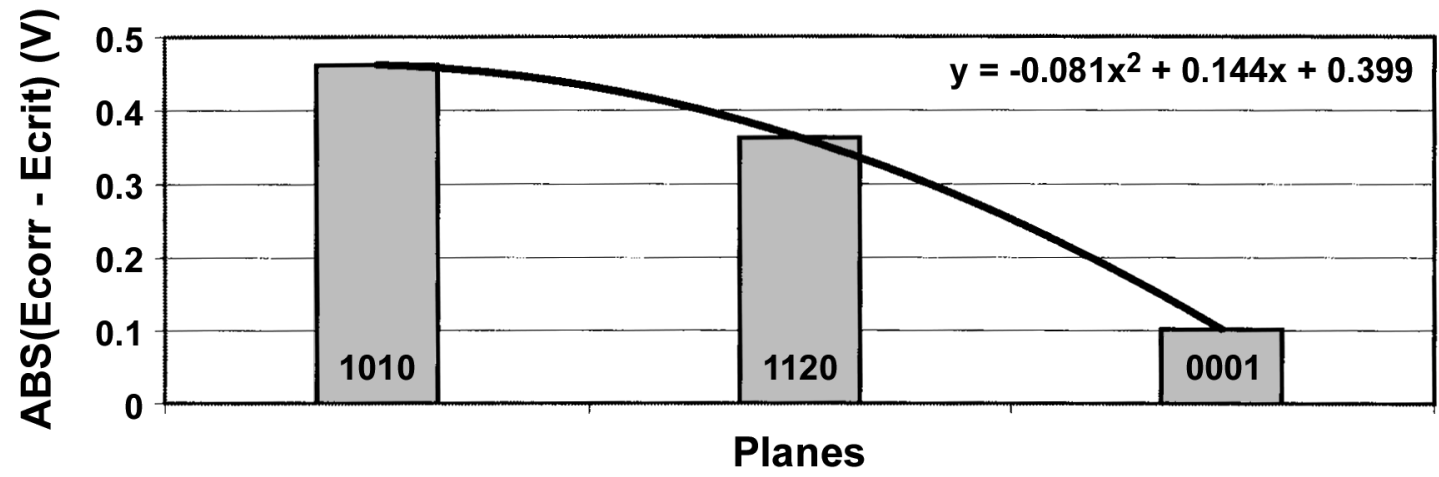

Planer Density of 3 Planes

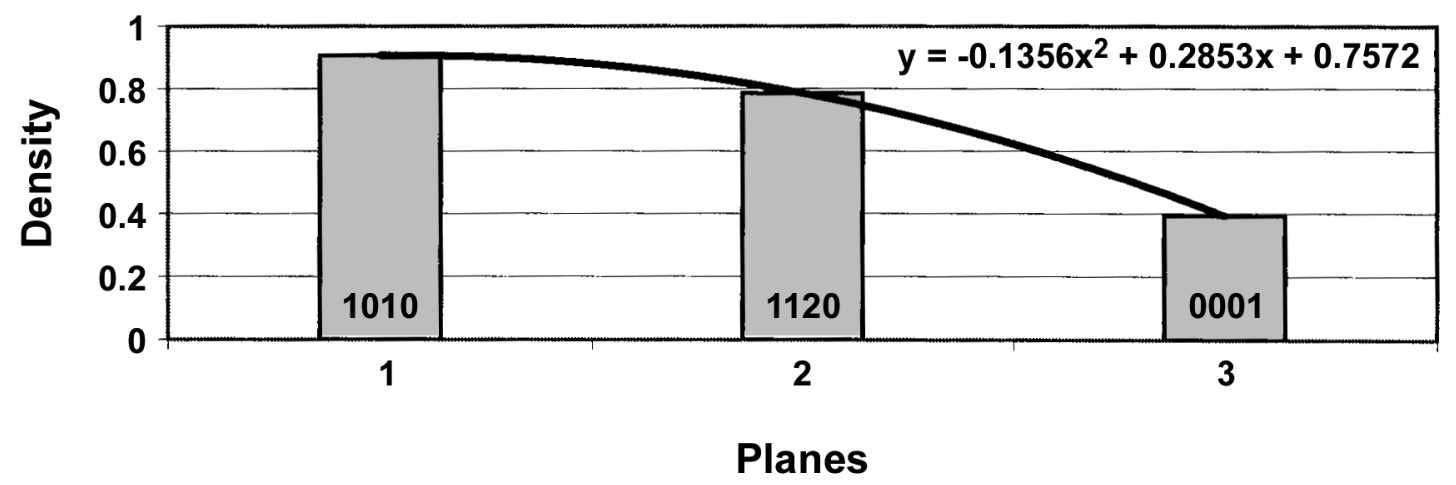

Figure 20. Similarities between planer density of the three planes and size of the passive range of the three planes.

\section{Single Crystal Pit Morphology}

Dramatic differences were also seen in the pit morphology using scanning electron microscopy. The pits viewed in the basal plane were distinctly noncrystallographic in structure. No crystallographically oriented fibers or trenches existed. This is contrary to a zinc single crystal study in which pits in the (0001) basal plane were distinctively crystallographic in structure. ${ }^{4}$ The perimeter of the pits are jagged, branched, not smoothly defined like the pits found in the polycrystalline specimens. SEM micrographs of the three different crystal planes are shown in Figures 21-23.

The two prism planes did show the crystallographically oriented fibers just as the polycrystalline specimens, but all fibers in pits on either of the prism planes were oriented in the same direction. Fibers in the (1010) prism plane were oriented in a different direction than the (1120) prism planes. This is consistent with the zinc single crystal study. The fact that we see fibers oriented in different directions between the two prism planes is probably due to the fact that we are looking at the regular stacking of the basal plane from different angles, as shown in Figure 24. Each polycrystalline specimen contained pits with fibers oriented in several directions indicating the presence of many crystals oriented in different directions. 

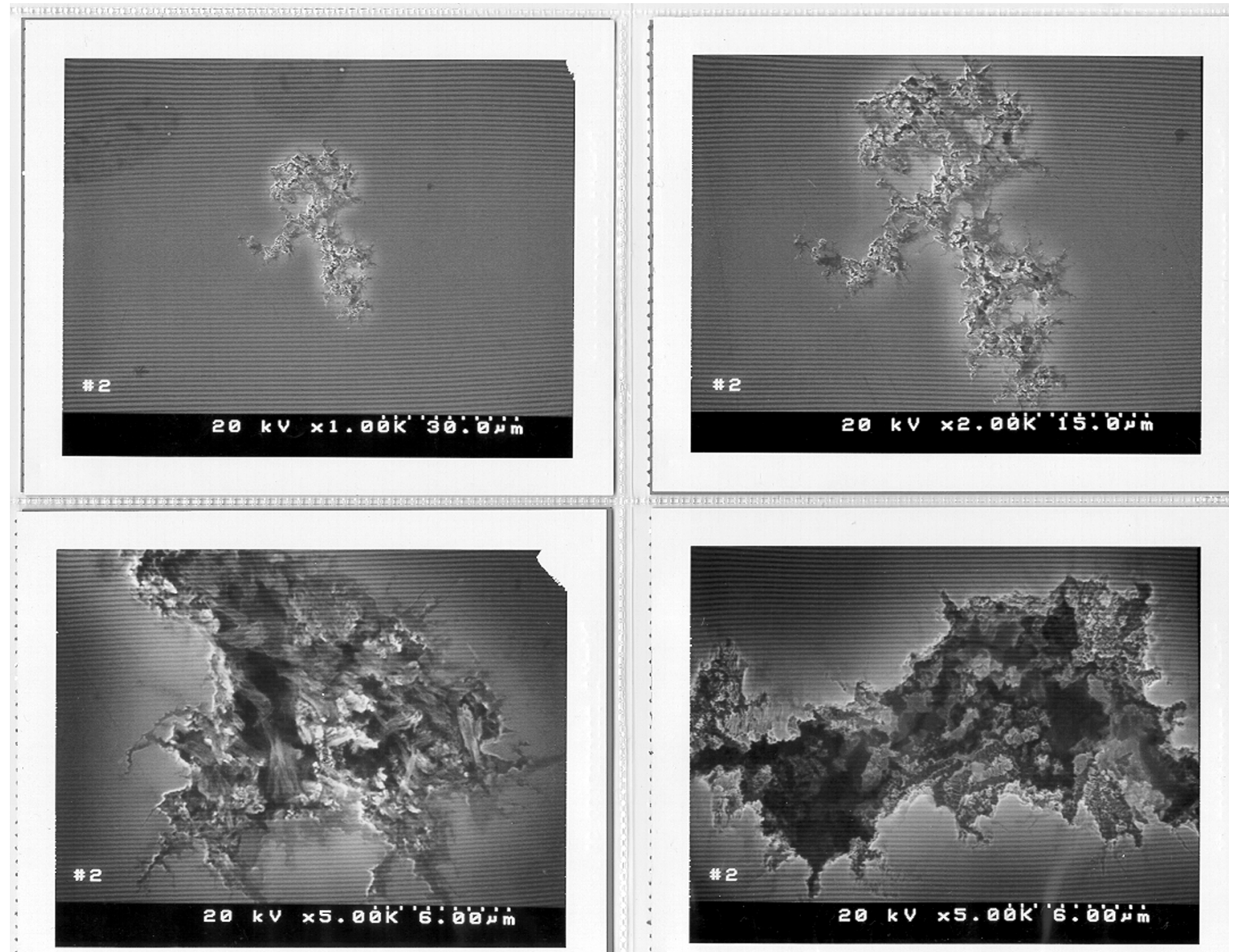

Figure 21. SEM micrographs of the 0001 basal plane.
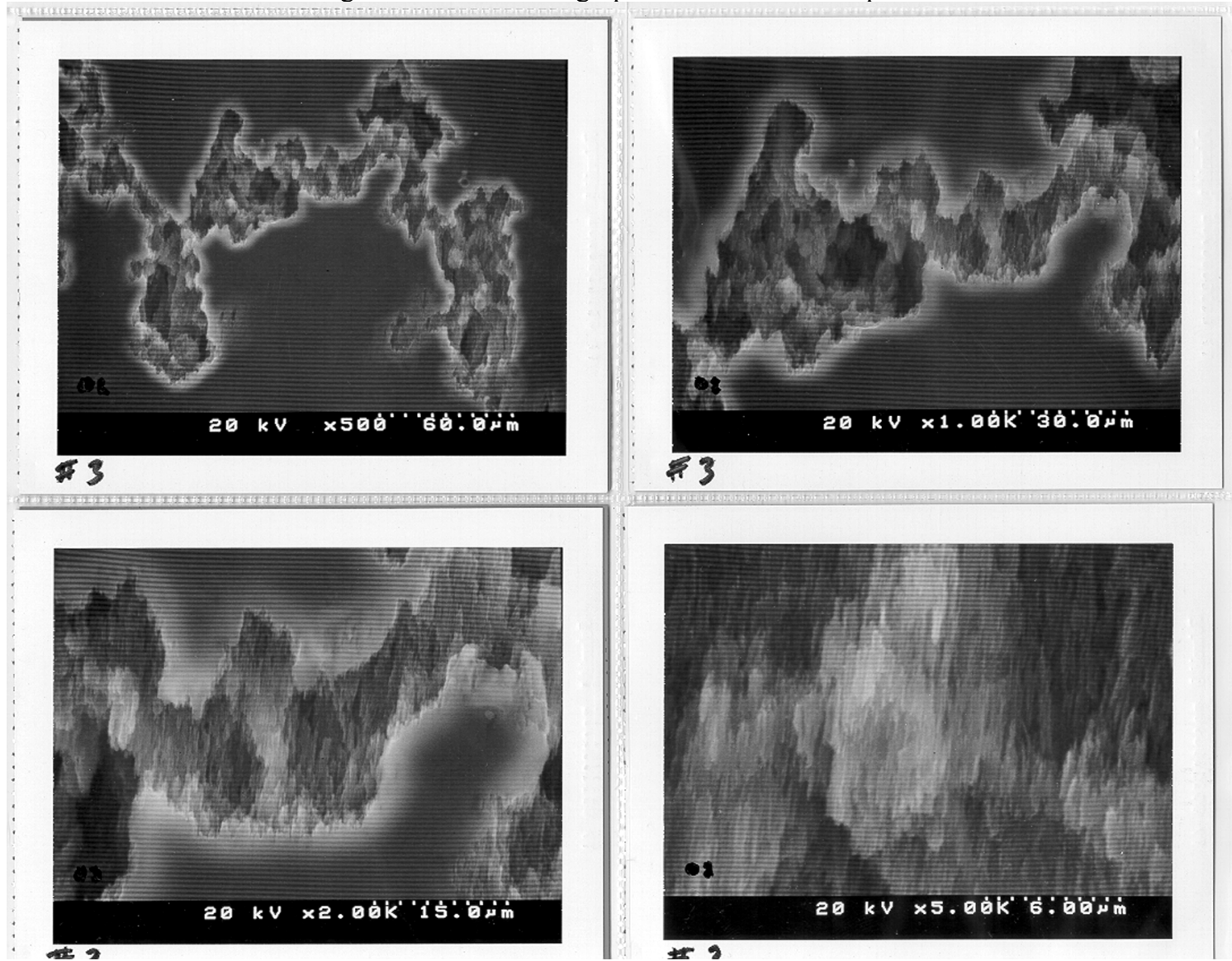

Figure 22. SEM micrograph of 1120 prism plane. 


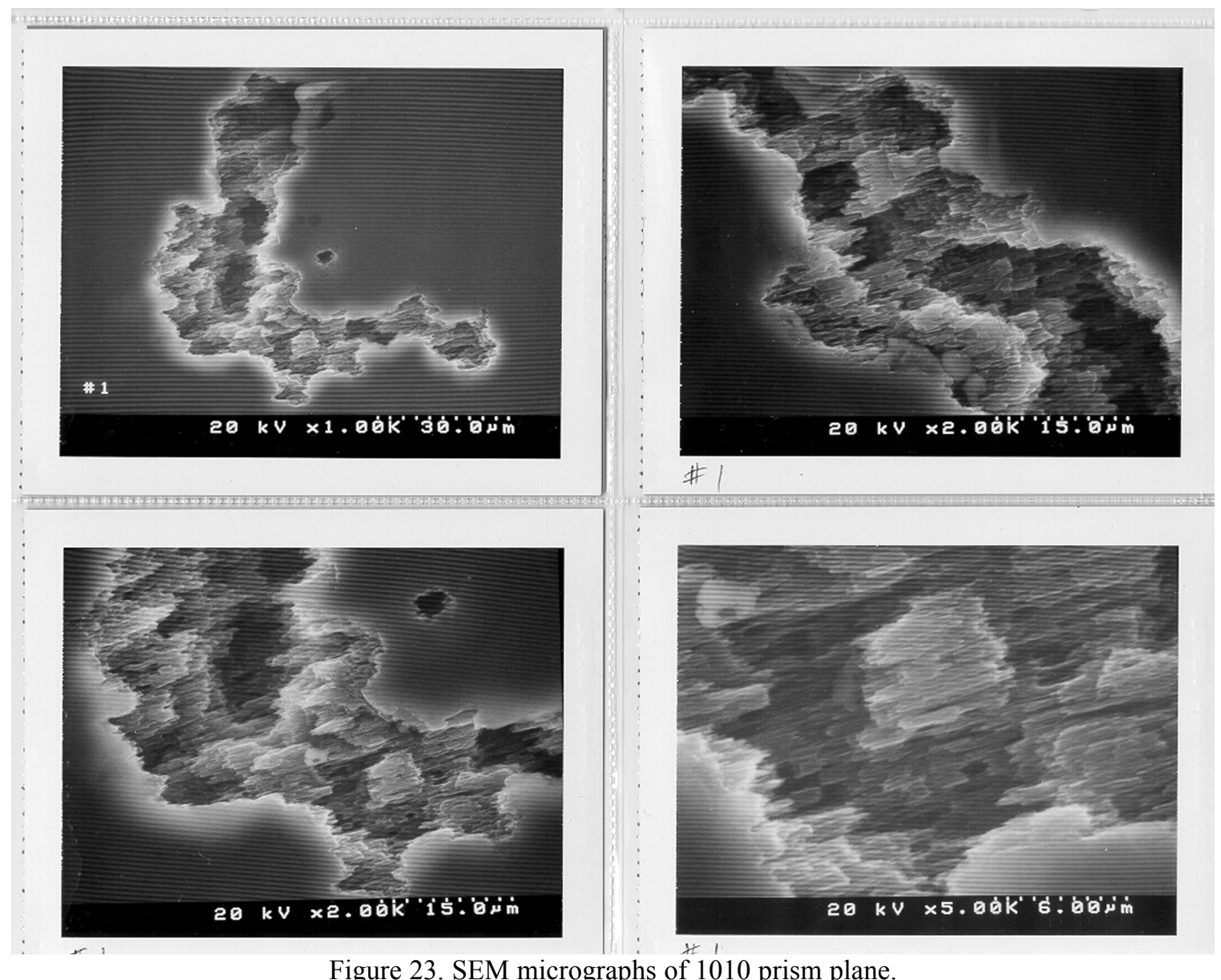

Figure 23. SEM micrographs of 1010 prism plane.

\section{View Looking Into Prism Planes}

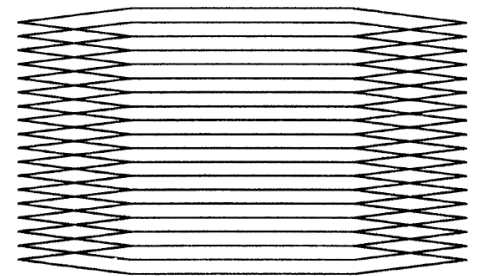

View Looking Into Basal Plane

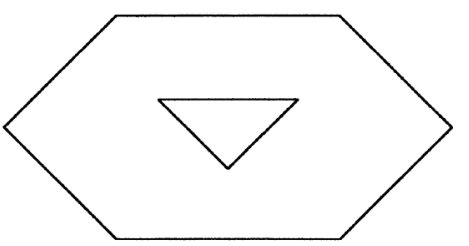

Figure 24. Drawing depicting views looking into side of basal planes and down into basal planes. 


\section{Conclusions}

The size of the passive range found on the cyclic polarization curves of polycrystalline beryllium appears to be a function of solution $\mathrm{pH}$ rather than of chloride concentration.

Examination of the pit morphology of the polycrystalline beryllium and the supportive observations of the clear differences of the pit morphology of the three single crystals with different crystallographic orientations suggest that corrosion of beryllium is strongly dependent on different crystallographic orientations.

We suggest that a dominant factor in the corrosion behavior of beryllium, for a particular environment, is the orientation of the individual grains. Since the production of structural grades of the beryllium usually results in an anistropic product, it follows that the corrosion behavior in a real product or research laboratory specimen will be different, depending on the orientation of the product in the original pressed billet. Further, the more modern grades of beryllium are more isotropic than early grades of beryllium. Hence, in assessing the corrosion of polycrystalline beryllium parts, the era in which the product was manufactured has to be recognized.

\section{Acknowledgements}

The authors would like to thank:

- Joe Farmer for use of his use of his lab space, lab equipment and technical advice

- Tony Gonis for his consultation and technical advice 


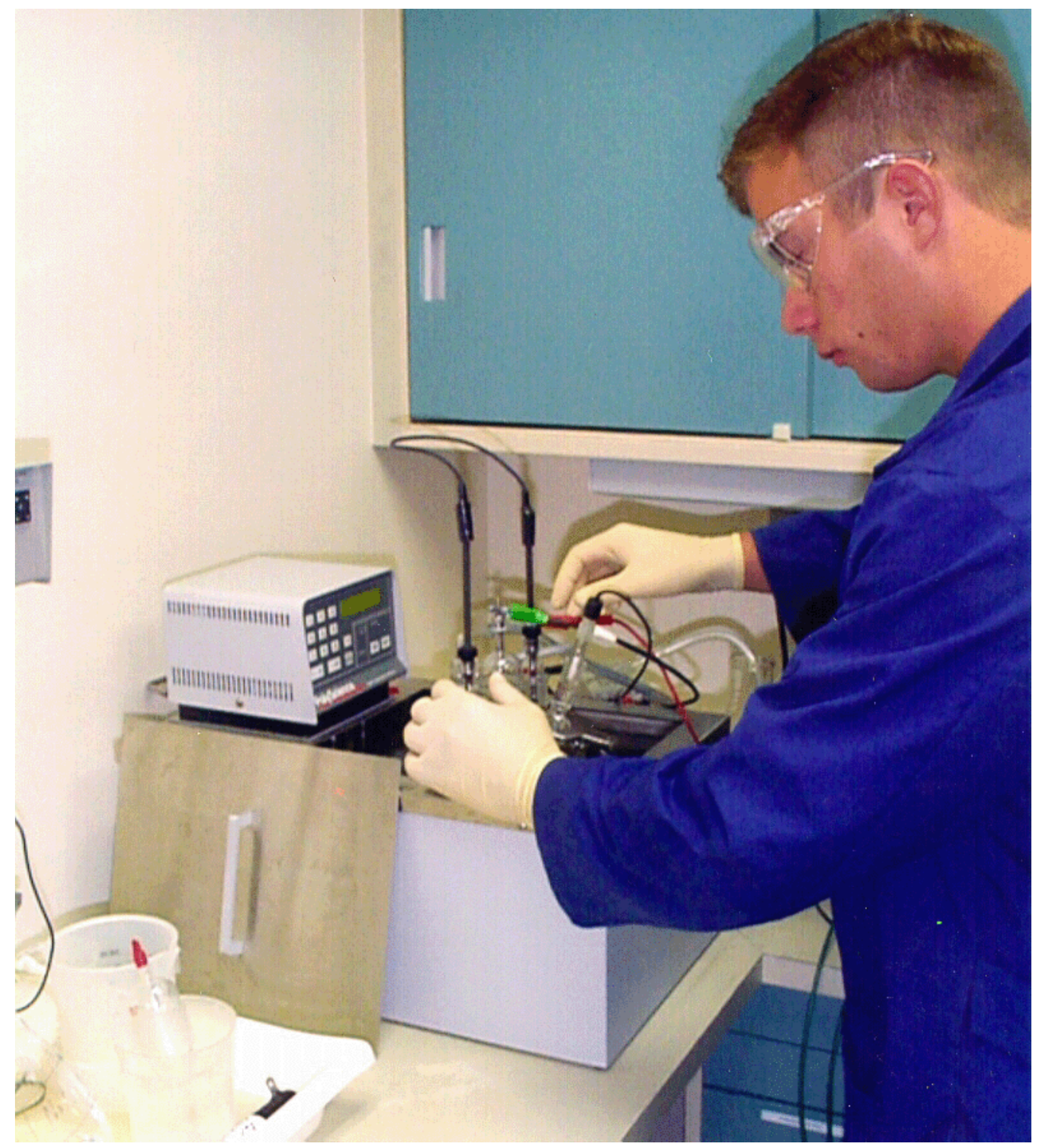

Jeff Friedman in Electrochemical Corrosion Lab (B235/R1120) carrying out a beryllium cyclic polarization test 